\title{
An integrated model for optimal selection of quality, maintenance, and production parameters with autocorrelated data
}

\author{
S. Jafarian-Namin ${ }^{1}$, M. S. Fallah Nezhad ${ }^{2,}{ }^{*}$, R. Tavakkoli-Moghaddam ${ }^{3}$, A. Salmasnia ${ }^{4}$ \\ and M. H. Abooie ${ }^{5}$ \\ 1Ph.D., Department of Industrial Engineering, Faculty of Engineering, Yazd University, Yazd, Iran \\ (samrad.jafarian@stu.yazd.ac.ir) \\ ${ }^{2}$ Associate Professor, Department of Industrial Engineering, Faculty of Engineering, Yazd University, Yazd, \\ Iran \\ (fallahnezhad@yazd.ac.ir) \\ ${ }^{3}$ Professor, School of Industrial Engineering, College of Engineering, University of Tehran, Tehran, Iran \\ (tavakoli@ut.ac.ir) \\ ${ }^{4}$ Associate Professor, Department of Industrial Engineering, Faculty of Technology and Engineering, \\ University of Qom, Qom, Iran \\ (a.salmasnia@qom.ac.ir) \\ ${ }^{5}$ Assistant Professor, Department of Industrial Engineering, Faculty of Engineering, Yazd University, Yazd, \\ Iran \\ (mhabooie@yazd.ac.ir)
}

\begin{abstract}
Statistical process monitoring, maintenance policy, and production have commonly been studied separately in the literature, whereas their integration can lead to more favorable conditions for the entire production system. Among all studies on integrated models, the underlying process is assumed to generate independent data. However, there are practical examples in which this assumption is violated because of the extraction of correlation patterns. Autocorrelation causes numerous false alarms when the process is in the in-control state or makes the traditional control charts react slowly to the detection of an out-of-control state. The autoregressive moving average (ARMA) control chart is selected as an effective tool for monitoring autocorrelated data. Therefore, an integrated model subject to some constraints is proposed to determine the optimal decision variables of the ARMA control chart, economic production quantity, and maintenance policy in the presence of autocorrelated data. Due to the complexity of the model, a particle swarm optimization (PSO) algorithm is applied to search for optimal decision variables. An industrial example and some comparisons are provided for more investigations. Moreover, sensitivity analysis is carried out to study the effects of model parameters on the solution of the economic-statistical design.
\end{abstract}

Keywords: Economic-statistical design, Economic production quantity, Maintenance policy, ARMA control chart, PSO algorithm.

\footnotetext{
* Corresponding author.

Address: Department of Industrial Engineering, Yazd University, P.O. BOX 89195-741, Pejoohesh Street, Safa-ieh, Yazd, Iran.

Office Phone: (+9835)31232548.

E-mail address: fallahnezhad@yazd.ac.ir (M.S. Fallah Nezhad).
} 


\section{Introduction}

The survival of producers in the world of competition with fast-changing markets and the spread of diversity in productions necessitates appropriate planning. In manufacturing systems, statistical process monitoring (SPM) and maintenance policy (MP) are conventional tools to decrease the fraction of nonconforming items. There exist several studies in which these concepts are treated separately. For instance, the subjects of SPM, MP, and economic production quantity (EPQ) were independently studied [1-3]. In recent years, the integration of production, maintenance, and quality has also attracted many researchers.

Control charts have gradually been approved in pioneer industries as effective tools used in statistical quality control to ensure quality and save manufacturing costs. It is mainly used to identify the change in the process before manufacturing nonconforming items in massive amounts. After introducing the basic theory of process monitoring by Shewhart, numerous control charts have been developed to achieve particular objectives under various assumptions [4]. One of the main assumptions of SPM is that the sampled observations at different time points must be independent. Nevertheless, the independence assumption is not realistic from two types of practical experiences: (1) sampling in high frequency induces autocorrelation in some processes and (2) sampling from processes, such as chemical and environmental, that introduce inherent autocorrelation [5]. In some industrial/non-industrial processes, such as continuous manufacturing processes, financial processes, health care systems, environmental phenomena, network monitoring, a correlation exists among adjacent observations [6]. The autocorrelation, if ignored, can lead to a significant influence on the statistical performance of traditional control charts [7].

This has led to the development of various control charts for autocorrelated data. Two model-based approaches can be used to treat the process when the serial correlation exists among observations. These approaches include the residual control charts and the modified control charts [8,9]. In the first approach, the control charts are applied to the residuals obtained after fitting a model to eliminate the correlated structure. The special cause chart (SCC) was proposed as an initial study of this approach [10]. In the second approach, the correlated observations are directly used on the control charts in which the control limits are adjusted according to the autocorrelation structure. The modified control chart was initially proposed in [11]. In addition to the introduced approaches, neural network-based control charts can also be categorized as the third approach in which the data are processed without necessity of identifying models or making adjustments [12]. Some recent studies using different approaches can be referred to in [13-15].

In SPM, we concentrate on modified control charts that benefit from plotting original observations and more straightforward interpretation by the operator. Of those, the autoregressive moving average (ARMA) control chart is selected as a suitable one to monitor a sequence of autocorrelated data [16]. ARMA control chart considers the autocorrelation structure of the underlying process and utilizes the advantages of EWMA control chart for stationary processes, known as EWMAST control chart [17] and SCC. 
The sample to be monitored by this chart is based on an ARMA statistic. It benefits from allowing a more flexible choice of parameters. Thus, the performance of this chart is related to the autocorrelation structure of the statistic. As it was shown for autocorrelated processes, if appropriate parameter values are chosen for an ARMA chart, its performance will be superior in comparison to SCC and EWMAST charts [16]. In this study, the underlying process is assumed to follow $\operatorname{ARMA}(1,1)$ model for two reasons: (1) being stationary, similar to most statistical process control systems, and (2) the existence of both autoregressive and moving average terms that makes it possible to examine their effects separately [18]. Since we aim to monitor the autocorrelation type of ARMA processes, the ARMA control chart is used in this study to determine its design parameters via optimizing an integrated model.

Generally, the design of a control chart needs optimally specifying a set of variables that depends on the type of the considered chart and provided assumptions. The design of the ARMA chart requires to specify sample size $(n)$, sampling interval $(h)$, control limits width $(I)$, moving average parameter $(\theta)$, and autoregressive parameter $(\phi)$. There can be found only five researches on the design of the ARMA chart according to the best of our knowledge. Low and Lin [19] optimally determined the design parameters of the ARMA chart by minimizing Duncan's cost function. They used Weibull distribution to present the time that the process shifts. An economical design (ED) of the ARMA chart was presented in [20] to optimally determine its design parameters by minimizing the cost function of Lorenzen and Vance (L\&V). Both [19] and [20] addressed only economic considerations and used a genetic algorithm (GA) for optimizations. However, EDs have been criticized for poor statistical properties, such as lower power in detecting shifts comparing to statistical designs (SD) that merely aim to decrease the occurrences of Type-I or Type-II errors. Based on the idea of economic-statistical design (ESD) using L\&V cost function, Costa and Fichera [21, 22] optimally designed the ARMA chart with fixed parameters and with variable sampling intervals (VSI). They devised a modified type of differential evolution for optimization.

Heretofore, we discussed the design and modeling of control charts with autocorrelated data. However, since the concepts of SPM, MP, and EPQ can be defined in a unified model, separately modeling them may provide suboptimal solutions. By realizing such dependency, it was shown that implementing MP can result in lower quality costs and the probability of system failure, as well as increasing the production of conforming items [23]. Hadidi et al. [24] divided the literature on such models into two general categories: (1) interrelated methods, in which a model is considered for one function bearing in mind the others, and (2) integrated models, in which two or more components are modeled simultaneously. In this paper, the second category is reviewed according to the proposed issue of monitoring autocorrelated data. There are integrated models including double concepts of SPM, MP, and EPQ in several studies to amend the performance of manufacturing systems. Since SPM has been considered the main subject, only its integrations with MP and EPQ are referred to in double designs.

In traditional production planning, it is assumed that the economic value of production is determined without occurring any defects and the associated costs. 
However, under real conditions, the process may be a shift to the out-of-control state. This, while affecting the quality of products, causes imposing some costs to the system. This research gap has attracted the attention of many researchers to link quality and production issues. Among the double integrations of these issues, the reader can refer to [25-30].

On the other hand, improving product quality and reducing downtime and operating costs can be addressed by two critical issues of quality control and maintenance policies that their goals overlap a great deal. Only using the programs to improve the quality of products is not enough because the operating conditions of the processes, which are examined based on the maintenance policies, also affect the quality of the products. Thus, integrating quality control and maintenance has been focused on by some researchers [31-43]. Recently, Farahani and Tohidi [44] reviewed the literature on this issue.

Although simultaneously considering the triple concepts plays an essential role in reducing the costs of manufacturing systems, few scholars have already studied this subject. Among them, Ben-Daya and Makhdoum [45] introduced an integrated model to specify the EPQ and SPM parameters under several preventive maintenance rules. Lam and Rahim [46] presented an integrated model of EPQ SPM, and MP for a deteriorating manufacturing system. Pan et al. [47] proposed a joint model of EPQ and MP for an imperfect production process based on a Shewhart control chart to minimize the cost function. Salmasnia et al. [48] modeled the integration of production run length, MP, and SPM in the presence of multiple assignable causes. Recently, new integrated models of triple concepts have been proposed, such as ESD under Variable Parameter (VP) control chart for monitoring multivariate quality characteristics [49], under non-uniform sampling by considering the time value of money and the stochastic shift size [50], under adaptive control chart [51], and under an adaptive non-central chi-square control chart [52].

The properties of the existing studies in the literature are briefly listed in Table 1. It is observed that there are not any studies on triple integrated models in which the independence assumption for the data being monitored is violated. To bridge the existing gaps in the literature:

- This study presents a model by integrating the concepts of SPM, MP, and EPQ,

- In contrast to most of the studies in the literature that consider independence assumption for the underlying process, this study uses a control chart to monitor autocorrelated data of type ARMA and its special cases as autoregressive (AR) and moving average (MA) processes,

- The proposed method aims to optimally determine the decision variables by minimizing the constrained cost function.

\{Please insert Table 1 about here.\}

The rest of this paper is organized as follows. In the next section, the structure of the ARMA control chart to monitor an autocorrelated process is briefly described in the second section. The integrated model is described in detail in the third section, and the 
proposed model is formalized according to a cost objective function subject to some constraints. In the fourth section, the solution approach based on particle swarm optimization (PSO) is explained. Then, in the next section, an industrial example is provided to illustrate the solution procedure and indicate the applicability of the proposed model. Furthermore, some comparative studies and sensitivity analysis are presented in this section. Finally, conclusions and further perspectives are presented.

\section{ARMA Control Chart}

The effectiveness of the ARMA control chart has been proved for monitoring autocorrelated data [16]. Suppose that the measured variable at time $t$, normally distributed with mean $\mu$ and variance $\sigma x^{2}$, is mathematically expressed by:

$$
X_{t}=u X_{t-1}+a_{t}-v a_{t-1}, \quad a_{t} \in N\left(0, \sigma_{a}^{2}\right)
$$

where the measurement at time $t-1$, and the noise factors at $t$ and $t-1$, characterized by $a_{t}$ and $a_{t-1}$ respectively, are linearly combined to present the current measurement $X_{t}$. The constants $u$ and $v$ are the AR and the MA coefficients, respectively, with conditions $|u|<1$ and $|v|<1$. The variance of this process is shown as:

$$
\sigma_{X}^{2}=\frac{1-2 u v+v^{2}}{1-u^{2}} \sigma_{a}^{2}
$$

The sample statistic to be monitored by the ARMA control chart at time $t$ is represented by:

$$
Z_{t}=\phi Z_{t-1}+\theta_{0} X_{t}-\theta X_{t-1}, \quad \theta_{0}=1+\theta-\phi
$$

where $\phi$ and $\theta$ are the AR and the MA parameters, respectively. Note that the conditions $|\phi|<1$ and $|\theta|<1$ must be satisfied to guarantee reversibility and stationary of the process being monitored. The mean of the sample statistic in Equation (3) is $\mu$, and the corresponding steady-state variance is as follows:

$$
\sigma_{Z}^{2}=\left[\frac{2(\theta-\phi)(1+\theta)}{1+\phi}+1\right] \sigma_{X}^{2}
$$

Accordingly, the upper and lower control limits of the ARMA chart are calculated by ( $I$ is the control limit coefficient):

$$
[L C L, U C L]=\left[\mu \pm l \sigma_{Z}\right]
$$

In this research, the data monitored by this control chart follow the ARMA process. Since the existence of autocorrelation, ARMA Simulation (AS) procedure is applied to approximately calculate average run length (ARL) values when the process states are 
in-control and out-of-control, respectively indicated by $A_{R} L_{0}$ and ARL 1 . In each simulation run, $M$ measurements in $S=500$ columns are generated based on a set of design parameters $(n, h, l, \phi, \theta)$. By considering $\mu_{0}=100$ and $\sigma_{x}{ }^{2}=10$, the steps of AS procedure can be summarized below:

Step 1. Calculate $\sigma_{a}$ from Equation (2) by selecting $u$ and $v$.

Step 2. Generate series $a_{i, j}, X_{i, j}$ and $X_{i, j}^{\prime}$ of size $M$ in $S$ columns by ( $\delta$ is the coefficient of the mean shift):

$$
\begin{aligned}
& a_{i, j} \square N\left(0, \sigma_{a}^{2}\right), \quad a_{0, j}=0, \quad X_{0, j}=\mu_{0}, \\
& X_{i, j}=C+u X_{i-1, j}+a_{i, j}, \\
& X_{i, j}^{\prime}=C+X_{i, j}+\delta \sigma_{X}, \quad \forall i=1, \ldots, M, \quad \forall j=1, \ldots, S
\end{aligned}
$$

Step 3. Set independent variables: $n, h, l, \phi, \theta$.

Step 4. Obtain the value of steady-state variance from Equation (4) by replacing the estimation of $\sigma_{X}$.

Step 5. Calculate control limits using Equation (5).

Step 6. Compute the run length (RL) values for $j=1, \ldots, S$ :

Step 6.1. Compute $R L_{0 j}$ until $L C L \leq Z_{i, j} \leq U C L$, where $Z_{i, j}$ is obtained by replacing $X_{i, j}$ in Equation (3),

Step 6.2. Compute $R L_{1 j}$ until $L C L \leq Z_{i, j} \leq U C L$, where $Z_{i, j}$ is obtained by replacing $X_{i, j}^{\prime}$ in Equation (3).

Step 7. Calculate ARLo and $\mathrm{ARL}_{1}$ by averaging them for $S=500$ times from Step 6.

\section{Model description}

In real production environments, the process possibly deteriorates over time due to a variety of specific causes. Such so-called imperfect manufacturing systems are in contrast to previous classical perfect systems that assume faultless production. In this study, an imperfect production process including quality, maintenance, and production concepts is investigated that operates in the in-control or out-of-control states. Accordingly, a model is proposed to optimize the cost function of the imperfect manufacturing system subject to some statistical constraints. Moreover, to be adapted to the situations that the independence assumption has deteriorated and the underlying process is autocorrelated, this study applies the ARMA control chart for the first time to notify the operators when the process shifts to the out-of-control state.

In the rest of this section, the main assumptions of modeling are first introduced. In the following subsection, different scenarios for the proposed model are defined. Then, the structure of the cost function is described. The proposed mathematical model is presented in the last subsection.

\subsection{Notations and assumptions}

The notations applied in this study can be seen in Table 2, which is categorized into four sets, including decision variables, indicators, time parameters, cost parameters, and process parameters. For simplifying the mathematical modeling, some assumptions are listed to be held as follows: 
1. The quality characteristic follows a Normal distribution, which its autocorrelation structure is of the type ARMA, including the cases as ARMA(1,1), AR(1), and MA(1),

2. The cycle always begins from the in-control state (i.e., $\mu=\mu_{0}$ ),

3. The in-control time of process follows a truncated Weibull distribution with scale parameter $\lambda>0$ and shape parameter $\gamma>0$ as (if $\gamma=1$, it changes to truncated Exponential distribution):

$$
f(t \mid(k+1) h)=\frac{\lambda \gamma(\lambda t)^{\gamma-1} e^{-(\lambda t)^{\gamma}}}{1-e^{-(\lambda(k+1) h)^{\gamma}}},
$$

4. Only one type of assignable cause exists. When it occurs, the process state shifts to the out-of-control as $\mu_{1}=\mu_{0}+\delta \sigma x$. Note that the variance remains unchanged,

5. Two types of maintenance policies may happen, including preventive maintenance (PM) and reactive maintenance (RM),

6. If after the $k^{\text {th }}$ sampling interval no signal is detected due to falling a point outside the control limits, PM is performed when the $(k+1)^{\text {th }}$ interval is terminated,

7. When the process shifts to the out-of-control state during the sampling intervals between 0 and $k$, the search for the assignable cause begins. At that time, RM is performed to restitute it to the initial condition,

8. The production cycle terminates when either RM is performed after a true signal from the control chart or if the $(k+1)^{\text {th }}$ sampling is implemented (each one occurs earlier),

9. The time required to run the reactive or the preventive maintenance, detection of the false signal, and sampling is considered negligible comparing to the time of the production cycle.

\{Please insert Table 2 about here.\}

\subsection{Scenarios description}

The production process begins from the in-control state, and when an assignable cause occurs, it shifts to the out-of-control state. Figure 1 shows three possible scenarios that may occur in an imperfect production process [49].

Scenario 1 occurs when the state of the process stays in-control for the whole time of the cycle. To ensure the reliability of the manufacturing process, preventive maintenance is implemented when the production cycle is terminated. If the process shifts to an out-of-control state and then this deviation is detected before the end of the cycle, Scenario 2 occurs. In this case, reactive maintenance is implemented to restore the process situation to the initial condition. Scenario 3 differs from Scenario 2 only in the disability of detecting the shift until the end of the cycle. In this case, PM is switched to RM when the shift is identified at the end. Here, each scenario is assumed to happen with probability [47]:

$\operatorname{Pr}\left(S c_{1}\right)=1-F((k+1) h)=e^{-(\lambda(k+1) h)^{\gamma}}$, 
$\operatorname{Pr}\left(S c_{2}\right)=F(k h) \operatorname{Pr}($ signaling $\mid$ out - of - control state $)$,

$\operatorname{Pr}\left(S c_{3}\right)=F((k+1) h)-F(k h) \operatorname{Pr}($ signaling $\mid$ out - of - control state $)$,

where $F($.$) is the cumulative function of the truncated Weibull distribution and$ $\operatorname{Pr}$ (signaling| out-of-control state) as the probability of triggering an alarm when the process shifts to out-of-control state, is expressed as (assuming that $\beta=1-\left(1 / A_{R} L_{1}\right)$ ):

$\operatorname{Pr}($ signaling $\mid$ out - of - control state $)=1-\beta^{k-1}$.

\{Please insert Figure 1 about here.\}

Moreover, the expected values of in-control time $\left(T_{\text {in }}\right)$ and out-of-control time $\left(T_{\text {out }}\right)$ in each scenario are calculated as follows [47]:

$$
\begin{aligned}
& E\left(T_{\text {in }} \mid S c_{1}\right)=(k+1) h, \\
& E\left(T_{\text {out }} \mid S c_{1}\right)=0, \\
& E\left(T_{\text {in }} \mid S c_{2}\right)=\int_{0}^{k h} t \times f(t \mid(k+1) h) d t, \\
& E\left(T_{\text {out }} \mid S c_{2}\right)=h \times A R L_{1}-\tau+n E+T_{1}, \\
& E\left(T_{\text {in }} \mid S c_{3}\right)=\int_{0}^{(k+1) h} t \times f(t \mid(k+1) h) d t, \\
& E\left(T_{\text {out }} \mid S c_{3}\right)=(k+1) h-E\left(T_{\text {in }} \mid S c_{3}\right),
\end{aligned}
$$

where $E$ indicates the time to sample and chart one item, $T_{1}$ is the time to detect the assignable cause, and $\tau$, denoting the expected time between the assignable cause occurrence and the next inspection, is written as:

$$
\tau=\int_{0}^{(k+1) h} t \times f(t \mid(k+1) h) d t-h\left(\sum_{y=1}^{k} e^{-(\lambda y h)^{\gamma}}-k e^{-(\lambda(k+1) h)^{\gamma}}\right) .
$$

\subsection{Structure of Cost Function}

At the beginning of this section, the expected values of the in-control time and the out-of-control time, as well as the occurrence probability of each scenario, were expressed. In this subsection, constituents of cost function, including the quality loss cost, the sampling cost, the maintenance cost, and inventory-related costs, are described.

\section{Quality loss cost}

The expected quality loss cost is expressed by:

$$
E(Q)=\sum_{r=1}^{3} E\left(C_{Q} \mid S c_{r}\right) \operatorname{Pr}\left(S c_{r}\right)
$$

The expected quality loss cost for each scenario is as follows: 
$E\left(C_{Q} \mid S c_{r}\right)=\left\{\begin{array}{cc}C_{\text {in }} \times E\left(T_{\text {in }} \mid S c_{r}\right), & r=1 \\ C_{\text {in }} \times E\left(T_{\text {in }} \mid S c_{r}\right)+C_{\text {out }} \times E\left(T_{\text {out }} \mid S c_{r}\right), & r=2,3\end{array}\right.$

where $C_{\text {in }}$ indicates the quality loss cost in the in-control state, $C_{\text {out }}$ shows the quality loss cost in the out-of-control state.

\section{Sampling cost}

The expected sampling cost per cycle time is presented by the following formula:

$$
E(S)=\sum_{r=1}^{3} E\left(C_{S} \mid S c_{r}\right) \operatorname{Pr}\left(S c_{r}\right)
$$

where the conditionally expected sampling cost per cycle time for each scenario is calculated as by ( $C_{f}$ and $C_{v}$ are fixed and variable costs of sampling):

$$
E\left(C_{S} \mid S c_{r}\right)=\left\{\begin{array}{cc}
\left(C_{f}+C_{v} n\right) k, & r=1,3 \\
\left(C_{f}+C_{v} n\right)\left(E\left(T_{\text {in }} \mid S c_{r}\right)+E\left(T_{\text {out }} \mid S c_{r}\right)\right) / h, & r=2
\end{array}\right.
$$

\section{Maintenance cost}

The expected maintenance cost per production cycle is computed as follows:

$$
E(M)=\sum_{r=1}^{3} E\left(C_{M} \mid S c_{r}\right) \operatorname{Pr}\left(S c_{r}\right)
$$

where the expected maintenance cost per production for each scenario is as follows:

$$
E\left(C_{M} \mid S c_{r}\right)= \begin{cases}\frac{k \times C_{y}}{A R L_{0}}+C_{p m}, & r=1 \\ \frac{s_{r} \times C_{Y}}{A R L_{0}}+C_{r m}, & r=2,3\end{cases}
$$

where $C_{Y}$ is the false alarm cost, $C_{p m}$, and $C_{r m}$ respectively represent $\mathrm{PM}$ and RM costs, and $s$ indicates the expected number of samples obtained when the state of the process is in-control:

$$
\begin{aligned}
& s_{2}=\sum_{y=1}^{k-1} y \times\left[F_{t}((y+1) h)-F_{t}(y h)=\sum_{y=1}^{k-1} e^{-(\lambda y h)^{\gamma}}-(k-1) e^{-(\lambda k h)^{\gamma}},\right. \\
& s_{3}=E\left[\text { number of samples taken while in -control } \mid S c_{3}\right]=\sum_{y=1}^{k} e^{-(\lambda y h)^{\gamma}}-k e^{-(\lambda(k+1) h)^{\gamma}} .
\end{aligned}
$$

\section{Inventory holding and set up costs}

The inventory holding cost (IHC) and setup cost (SUC) are respectively expressed by: 


$$
\begin{aligned}
& I H C=\frac{B \times Q}{2}\left(1-\frac{d}{p}\right)=\frac{B \times T \times(p-d)}{2}, \\
& S U C=\frac{D \times A}{p \times T},
\end{aligned}
$$

where $B$ is the inventory holding cost per unit time, $d$ is the daily demand, $A$ is the setup cost per production, and $T$ characterizes the process cycle time. Since the process cycle operates for the $(k+1) h$ time units, the value of $T$ is defined as equal to it [47]. Afterward, the summation of inventory costs is defined as $E(I)=I H C+S U C$.

According to the concepts mentioned above, the expected total cost (ETC) is given by:

$E T C=E(Q)+E(S)+E(M)+E(I)$.

Moreover, the economic production quantity can be computed by:

$$
Q=p \times T .
$$

\subsection{Proposed Model}

To achieve an ESD, Equation (26) is used as the objective function by employing some constraints. The proposed model, called integrated-QIM model, is explained by:

Min ETC

s.t.

$$
\begin{aligned}
& A R L_{0} \geq A R L_{0}^{\min } \\
& A R L_{1} \leq A R L_{1}^{\max } \\
& k h \geq R_{I n t} \\
& n E \leq h \\
& n_{\text {min }} \leq n \leq n_{\max }, \quad h_{\min } \leq h \leq h_{\max } \\
& l_{\text {min }} \leq l \leq l_{\text {max }}, \quad k_{\text {min }} \leq k \leq k_{\text {max }} \\
& \theta_{\text {min }} \leq \theta \leq \theta_{\max }, \quad \phi_{\min } \leq \phi \leq \phi_{\max } \\
& n, k \in N^{+} ; h, l>0 ; \theta, \phi \in R
\end{aligned}
$$

where a minimum value for $A R L_{0}$ is considered that maintains a reasonable average run length when a false alarm occurs. Moreover, a maximum value is dedicated to $A R L_{1}$ to provide an appropriate average run length for a shifted process. To ensure the continuity of the process, the interval for the PM policy is regulated by $k h \geq R$ Int. Constraint $n E \leq h$ guarantees the applicability of obtained solutions by declining sets of design parameters that the time required to take and chart samples of size $n$ goes outside the sampling interval. Moreover, the design parameters $n, h, l, k, \theta$, and $\phi$ are set between lower and upper bounds (note that $n$ and $k$ are discrete positive values and the others are continuous). These extreme values may be determined as desired bounds by the decision-maker (DM) or quality engineers. Briefly speaking, we altered the model in [49] 
by: (1) using ARMA control chart, (2) considering $A R L_{0}$ and $A R L_{1}$ as statistical constraints, (3) ensuring the continuity of process and applicability of solutions respectively by defining two constraints, and (4) adding constraints for the AR and the MA coefficients. Through optimization of the proposed model, six decision variables (i.e., $n, h, l, k, \theta$, and $\phi$ ) are determined.

As shown in the model, there exist four constraints. To transform the model into an unconstrained one, an appropriate penalty function can be defined to converge to the best solutions through optimization. Any violation from the constraints must be added to the objective function such that the solution is pushed back towards the feasible region. The penalized objective function is defined for solution $S$ as follows.

$f p(S)=E T C(S) \times\left(1+\operatorname{viol}_{0}(S)+\operatorname{viol}_{1}(S)+\operatorname{viol}_{2}(S)+\operatorname{viol}_{3}(S)\right)$,

where $\quad \operatorname{viol}_{0}(S)=\max \left(0, \quad 1-\left(A R L_{0} / A R L_{0}{ }^{\min }\right)\right), \quad \operatorname{viol}_{1}(S)=\max \left(0, \quad\left(A R L_{1} / A R L_{1}{ }^{\max }\right)-1\right)$, $\operatorname{viol}_{2}(S)=\max \left(0,1-\left(k h / R_{I n t}\right)\right)$, and $\operatorname{viol}_{3}(S)=\max (0,(n E / h)-1)$ are the violations from the corresponding constraints in Equation (28). In the next section, an approach to optimize the model is provided.

\section{Solution Approach}

By considering the proposed mathematical model in the previous section, a non-linear programming (NLP) model under four constraints are solved. In the model, three decision variables, including $l, \theta$, and $\phi$, are only used for computing $A R L$ values, and the objective function is indirectly affected by these variables. Moreover, solution space is non-convex because both continuous and discrete decision variables exist in the model. According to the mentioned reasons, exact methods cannot be helpful because the model is not solvable or its run requires much more time. Thus, meta-heuristic algorithms can be applied to obtain near-optimal solutions in a reasonable time for such complicated models. Among those, GA and PSO have already been used to solve similar models. Some applications of the GA to solve similar models can be found for ED of ARMA control chart [20], ED of the variable sampling interval control chart [53], and robust ESD of the acceptance control chart [54].

Swarm algorithms (SAs) are stochastic population-based meta-heuristic algorithms that utilize imitating the processes of decentralized, self-organized systems. The most successfully applied SAs for solving the models of the control chart design is PSO [55]. It is a stochastic, population-based algorithm with unique searching ability by incorporating local and global searches. The optimization approach in PSO stems from the social behavior of birds, fishes, and so on. In addition to the powerful searching mechanism, some other advantages for its wide applications include computational efficiency and easy execution.

PSO has shown good performance in discontinues space to solve the non-linear mathematical models of control chart design. For ESD of the X-bar control chart, Chih et al. [56] optimized their proposed model by adapting PSO to cope with mixed continuous-discrete variables. Moreover, they found PSO more suitable and faster in convergence to the optimality compared to GA for designing the chart. Morabi et al. [57] 
solved the multi-objective model of this control chart using a hybrid epsilon constraint PSO. Salmasnia et al. [49] utilized PSO to optimize the cost function of integrating EPQ MP, and VP-T ${ }^{2}$ chart design subject to statistical constraints. In another study of integrating MP and control chart design for series systems, a robust optimization approach was presented utilizing PSO to minimize model costs under uncertain parameters [58]. Since the proposed model is also of non-linear type in the presence of both discrete and continuous variables, we employ PSO to optimize our proposed model according to the following steps.

Step 1. Initialization. Set the bounds on decision variables according to DM's considerations and the PSO parameters. Represent each solution as a particle by position $x_{i} t=[n, h, l, k, \theta, \phi]$ and velocity $V_{i} t$ in the iteration $t$. Then, for each particle $i=1$, ..., $N$ :

- Based on Uniform distribution, generate the initial value of position for each particle using a random vector $x_{i} \sqcup U\left(b_{l}, b_{u}\right)$ and the initial value of velocity according to $V_{i} \sqcup U\left(-\left|b_{u^{-}} b_{l}\right|,\left|b_{u^{-}} b_{l}\right|\right)$, where $b_{l}$ and $b_{u}$ are indications of lower and upper limits of the search space, respectively.

- Initialize the pbest of each particle equal to its initial position as pbest $_{i} \rightarrow x_{i}$ (note that pbest, called personal best, is the best value experienced by the $i^{t h}$ particle).

- By calculating the penalized objective function according to (29), if $f p\left(\right.$ pbest $\left._{i}\right) \leq f p$ (gbest), update gbest $\rightarrow$ pbest $_{i}$ (the best solution found so far, called global best, is indicated by gbest).

Step 2. Repetition. Since the behavior of any particle is affected by the current velocity, the personal best, and the global best, it is necessary to update the velocity and the position in each iteration (note that we have $i=1, \ldots, N$ for each particle ( $N$ indicates the population size) and $d i=1, \ldots, n_{d i}$ for the dimension of each particle):

- Generate random numbers $r_{p}$ and $r_{g}$ from $U\left(b_{l}, b_{u}\right)$.

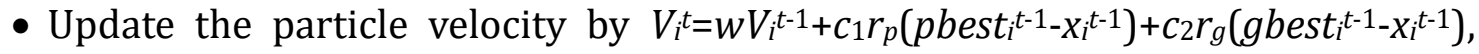
where $c_{1}$ and $c_{2}$ are respectively cognition and social learning factors, and $w$ is an inertia weight.

- Update the particle position by $x_{i}^{t}=X_{i} t^{t-1}+V_{i}{ }^{t}$.

- If $f p\left(x_{i}\right) \leq f p\left(p b e s t_{i}\right)$, update pbest of each particle.

- If $f p\left(p b e s t_{i}\right) \leq f p(g b e s t)$, update gbest.

Step 3. Stopping. If a predetermined number of iterations $(m)$ is achieved or a solution with an acceptable objective function amount is attained, stop. The latest gbest holds the best solution achieved. Otherwise, go to Step 2 .

Besides continuous decision variables in this study, there are discrete variables including $n$ and $k$. To transform the discrete variables to the continuous, it is assumed that $R v_{1}$ and $R v_{2}$ are respectively two random digits that belong to the interval $(0,1)$ corresponding to $n$ and $k$. Thus, the selected continuous values are transformed into discrete values by using the following formulas: 


$$
\begin{aligned}
& n=\min \left(n^{\min }+\left[R v_{1}\left(n^{\max }-n^{\min }+1\right)\right], n^{\max }\right), \\
& k=\min \left(k^{\min }+\left[R v_{2}\left(k^{\max }-k^{\min }+1\right)\right], k^{\max }\right),
\end{aligned}
$$

The values of cognition and social learning factors are usually considered so that their summation be equal to $c_{1}+c_{2}=4$. Costa and Fichera [21] calibrated the factors of PSO for ESD of the ARMA control chart. We also tune the most suitable factors of PSO in Section 5 to better fit the problem at hand.

\section{Experimental results}

As pointed out earlier, it is aimed to optimize the proposed mathematical model with the cost function of the production cycle subject to some statistical constraints. To indicate the applicability and validate the effectiveness of the proposed model, several numerical examples are studied in this section. In subsection 5.1, an industrial example is extended for the current study. Then, numerous comparisons are represented in subsection 5.2 for performance evaluations. In the last subsection, a sensitivity analysis is implemented to investigate the effects of some parameters on the solutions.

\subsection{Numerical example}

To illustrate the determination of decision variables via optimizing the proposed model, an industrial example is investigated. Consider a company with 125 working days/year, which sells a certain food product to a wholesaler in packages marked with the definite weight. Table 3 shows the nominal values of parameters adapted from [47] and those related to the ARMA control chart according to [21]. Since $u=0.475$ and $v=0.00$, the autocorrelation structure is $\operatorname{ARMA}(1,0)$ or $\operatorname{AR}(1)$. Moreover, the truncated Exponential distribution is investigated as a special case of truncated Weibull by setting $\gamma=1$. This example is simplified accordingly (the general assumptions are investigated in subsections 5.2 and 5.3). The number of simulations is set to 500 to calculate $A R L s$ according to AS procedure. In real applications, some priorities necessitate assigning limits on the decision variables and bounds on constraints to determine feasible space. Bearing in mind such circumstances, the integrated-QIM model is rewritten as follows:

Min ETC

s.t.

$$
\begin{aligned}
& A R L_{0} \geq 200 \\
& A R L_{1} \leq 10 \\
& k h \geq 5 \\
& n E \leq h \\
& 1 \leq n \leq 20, \quad 0.01 \leq h \leq 6 \\
& 0.001 \leq l \leq 5, \quad 1 \leq k \leq 70 \\
& 0.001 \leq \theta \leq 0.999, \quad 0.001 \leq \phi \leq 0.999
\end{aligned}
$$


\{Please insert Table 3 about here.\}

Once the PSO algorithm is implemented, an appropriate configuration of its influencing factors should be predetermined. We employed the L9 orthogonal array experimental design to specify the factors of PSO for the current minimization problem, in which the characteristic of ETC is of type the smaller-the-better. As shown in Table 4, three levels of each factor must be planned. For the L9 orthogonal array experimental design, nine distinct level configurations of assigning the factors are provided as individual trials according to Table 5 . For the $i^{\text {th }}$ trial, three optimal objective functions, including $E T C_{i 1}, E T C_{i 2}$, and $E T C_{i 3}$, are obtained using the PSO. Then, these outcomes are converted into a signal-to-noise $(\mathrm{S} / \mathrm{N})$ ratio via the following Equation [56]:

$$
\left(\frac{S}{N}\right)_{i}=-10 \log \left(\frac{1}{3} \sum_{j=1}^{3} E T C_{i j}^{2}\right), \quad i=1,2, \ldots, 9
$$

The results of calculating $\mathrm{S} / \mathrm{N}$ ratios using Minitab 18 software are recorded in the last column of Table 5. For different levels of PSO factors, Table 6 is constructed by computing $\mathrm{S} / \mathrm{N}$ ratios. The best level configuration of the factors is specified based on a maximal S/N ratio at each level for each factor since the characteristic of $\mathrm{S} / \mathrm{N}$ ratio is of type the larger-the-better. Considering the main factors plot for $\mathrm{S} / \mathrm{N}$ ratios from Figure 2 accompanied by the results of Table 6 , the best level of each factor is set at $w=1.2,(c 1$, $\left.c_{2}\right)=(2,2), N=80$, and $m=150$. Afterward, this configuration is used to optimally specify the values of decision variables by minimizing the model.

\{Please insert Table 4 about here.\}

\{Please insert Table 5 about here.\}

\{Please insert Table 6 about here.\}

\{Please insert Figure 2 about here.\}

The proposed model, by considering the nominal values of parameters mentioned earlier and the best configuration of PSO factors, is solved by the PSO algorithm under a program coded using MATLAB (R2016b). The optimal solution is attained as follows:

$\{n, h, l, k, \theta, \phi\}=\{1,0.227,2.738,22,0.000,0.617\}, \quad E T C_{Q I M}^{*}=4934.12, \quad E P Q=Q^{*}=523.50$

Accordingly, it is suggested to set the control limits at 2.738. Moreover, a sample size of 1 should be inspected every 0.227 hours (i.e., 817 seconds). After inspecting 22 samples consecutively, PM should be employed if the process remains under control during the whole cycle. Also, $A R L_{0}$ and $A R L_{1}$ values are respectively obtained as 279.12 and 5.02 that indicate the proper performance of the ARMA chart. In this model, with an expected total cost of 4934.12 , the economic production quantity of 523.50 is optimally obtained. The total demand for 10000 can be produced after about 20 production cycles 
(10000 divided by 523.50 equals 19.10$)$.

\subsection{Comparisons}

To validate the effectiveness of our model for the problem of having the autocorrelation structure among data, extensive comparisons are presented here based on different aspects: (1) comparison between models with and without integrating quality, inventory, and maintenance concepts, and (2) comparison the control charts for monitoring ARMA process including its special cases.

\subsubsection{Comparison between integrated and joint models}

This subsection is dedicated to the performance comparison of the integrated-QIM model with a model called joint-QIM. Quality, inventory, and maintenance decision variables are separately optimized according to this model. The procedure of calculating ETC for the joint-QIM is presented in the following steps:

1. The summation of inventory costs, i.e. $I H C$ and $S U C$, is minimized to obtain an optimal value of process cycle time $(T)$,

2. The decision variables of the ARMA chart, i.e. $n, h, l, \theta$, and $\phi$, are optimally attained by minimizing the summation of quality loss cost and sampling cost.

3. Using the values of $T$ and $h$ obtained previously, $k$ is calculated as $k=(T / h)-1$,

4. Finally, all six decision variables are embedded in the integrated objective function to calculate ETC for the joint-QIM.

Table 7 shows the obtained results of comparing the models. It can be seen that the value of ETC is decreased using the integrated model. Moreover, $A R L$ values are improved in comparison to those of the joint-QIM. We also provided the details of the cost function. The total expected costs of quality loss and maintenance are decreased using the integrated model. Instead, the joint-QIM provides lower costs of sampling and inventory.

\{Please insert Table 7 about here.\}

For more investigations, we compare these models by considering different AR and MA parameters for the numerical example presented previously. The underlying process includes $\operatorname{AR}(1)$ when $u \neq 0$ and $v=0, \operatorname{MA}(1)$ when $u=0$ and $v \neq 0$, and $\operatorname{ARMA}(1,1)$ when $u \neq 0$ and $v \neq 0$. Accordingly, 16 trials were performed. As shown in Table 8 , the results of cost savings confirm that integration of quality, inventory, and maintenance concepts leads to lower ETC than the joint-QIM. The lowest cost-saving, i.e. 272.56, is experienced in the $12^{\text {th }}$ trial where ETC values by integrated and joint models are respectively 4903.75 and 5176.31. Investigating the effects of ARMA parameters indicates that increasing $u$ and decreasing $v$ lead to higher ETC values.

\{Please insert Table 8 about here.\}

\subsubsection{Comparison among monitoring techniques}

The better statistical performance of the ARMA control chart for monitoring 
autocorrelated data was confirmed in [16] comparing to EWMAST and SCC charts. However, it is necessary to investigate their performance in the framework of ESD. These monitoring techniques have different mechanisms, and their performance depends on the chosen values of the design parameters. We previously described how to design the ARMA control chart. Designing SCC needs to fit a model on series of data to obtain uncorrelated ones. Then, the traditional monitoring technique under the independence assumption is applied to the uncorrelated data [10]. Using SCC in the framework of the integrated-QIM model, the decision variables include $n, h, l$, and $k$. The design of EWMAST requires setting an integer $m$ for approximating the variance and a smoothing coefficient $\lambda_{E}$ as well as $n, h, l$, and $k$. We set $m=25$ and $\lambda_{E}=0.2$ as suggested in [17].

To confirm the economic and statistical performance of our model, the results of applying ARMA, EWMAST, and SCC monitoring techniques are compared. We use the information presented in Table 3 by considering different combinations of ARMA coefficients from [16] to include AR(1) and ARMA(1,1). For the $6^{\text {th }}$ and $7^{\text {th }}$ combinations of $[u, v]$, infeasible solutions are obtained since the constraint of $A R L_{1}$ is not satisfied. Therefore, we relaxed the second constraint in the proposed model to get feasible solutions. Table 9 shows the results. The lowest ETC is bolded for different comparisons. It can be deduced that using the ARMA monitoring technique in the proposed model generally results in the lowest ETC. For $[u, v]=[0.95,0.45]$, the optimal solutions of ARMA, EWMAST, and SCC control charts are respectively attained in detail as follows:

$$
\begin{aligned}
& \{n, h, l, k, \theta, \phi\}=\{1,0.11,2.39,46,0,0.01\}, \quad E T C_{Q I M}^{*}=4988, E P Q=Q^{*}=517, A R L_{0}=206, \quad A R L_{1}=10 \text {, } \\
& \left\{n, h, l, k, \lambda_{E}, m\right\}=\{1,0.2,2.01,25,0.2,25\}, \quad E T C_{Q I M}^{*}=5026, \quad E P Q=Q^{*}=520, \quad A R L_{0}=202, \quad A R L_{1}=16 \text {, } \\
& \{n, h, l, k\}=\{1,0.1,2.83,50\}, \quad E T C_{Q I M}^{*}=5187, \quad E P Q=Q^{*}=510, \quad A R L_{0}=206, \quad A R L_{1}=136 .
\end{aligned}
$$

\{Please insert Table 9 about here.\}

\subsection{Sensitivity analysis}

The effects of various parameters on the solution of the proposed model are studied via sensitivity analysis. This is performed using the orthogonal-array Taguchi design and multiple regression. ETC is considered a dependent variable, and sixteen independent variables are treated as factors. Their level plans are shown in Table 10.

Table 11 shows how independent variables are assigned to the trials of L54 array. For each trial, the PSO is used to obtain the optimal solutions of the model. We changed the upper bound of the second constraint from 10 to 40 in the proposed model to get feasible solutions in all trials. The output of the optimizations is recorded in Table 12. Minitab 18 software is used to analyze the results. Table 13 shows the output for ETC. Assuming a significance level of 0.1 , the parameters $\delta, \lambda, \gamma, C_{i n}, C_{p m}, C_{r m}, A$, and $B$ are significant. For each factor in Table 14, the difference between two levels with the highest and lowest values is calculated and recorded in the Delta row. These values indicate how much the change in the levels affects ETC values in average. Accordingly, the ranking is done from the largest Delta value to the smallest. Among the significant factors, the greatest impact on ETC can be expected by changing $C_{i n}$ levels. 
The effects of different levels of factors on ETC in average are also shown in Figure 3. Since ETC is of type the smaller-the better, the levels that result in the lowest mean of ETC are preferred. A larger $\delta$ generally reduces ETC because it can be easily detected by the control chart and thus can be fixed just in time. Similarly, a higher value of $\gamma$ causes a reduction in ETC. In contrast, larger values of $\lambda, C_{i n}, C_{p m}, C_{r m}, A$, and $B$ lead to the higher ETC values.

The adequacy of the model can be visually checked from Figure 4. Figure 4(a) is a graphical plot of Normal probabilities versus residuals. It is seen that the points are appropriately fit on the line. The p-value for the Anderson-Darling (AD) test of residuals is 0.177 . This value is greater than the significance level of 0.05 . Thus, there is no evidence to reject the Normality assumption. It appears from Figure 4(b) that the residuals are randomly scattered around zero. In other words, there is no evidence of non-constant variance or missing term in the model. However, residuals related to trials 16,20 ,and 41 are outliers since their standardized values, respectively as $2.52,3.05$, and -2.23 , are out of the bounds of $[-2,+2]$ in the significance level of 0.05 . We left it without more investigations. From Figure 4(c), the symmetry of the distribution is inferred to some extent. Figure 4(d) shows no evidence that the residuals are correlated with one another. Therefore, the adequacy of the model is confirmed.

\{Please insert Table 10 about here.\} \{Please insert Table 11 about here.\}

\{Please insert Table 12 about here.\}

\{Please insert Table 13 about here.\}

\{Please insert Table 14 about here.\}

\{Please insert Figure 3 about here.\}

\{Please insert Figure 4 about here.\}

\section{Conclusions}

In this study, we aimed at bridging the gap between traditional perfect production models and the real production conditions. Therefore, we proposed a model for the imperfect production process by integrating the triple concepts of SPM, MP, and EPQ. In some processes, the assumption that the data derived from the process are independent may not be true. The existence of autocorrelation among those data can lead to significant effects on the statistical performances of control charts if ignored.

Therefore, in contrast to most of the researches in the literature, we considered the first-order autoregressive moving average structure for the underlying process as well as its special cases, i.e. AR and MA. Since Jiang et al. [16] showed that the ARMA control chart, compared to EWMAST, and SCC charts, was more effective for monitoring a process with autocorrelated data, we also applied the ARMA chart in this study.

For optimizing the proposed integrated economic-statistical model, a PSO algorithm was used to determine decision variables. Finally, this procedure was illustrated through an industrial example, some comparisons were made for validation, and the sensitivity analysis was finally implemented to distinguish the effects of the parameters on the 
objective function.

The results of comparative studies indicated that: (1) the integration of quality, inventory, and maintenance concepts leads to the significantly reduced expected total cost in comparison to the joint-QIM model, (2) using the ARMA chart as a monitoring method in the proposed model generally results in the lowest expected total cost in comparison to EWMAST and SCC control charts, and (3) increasing AR and decreasing MA constants of the underlying ARMA process have adverse effects on the values of ETC. Besides, the results of sensitivity analysis confirmed that the shift magnitude in the process mean and the shape parameter of the truncated Weibull distribution have inverse relationships with ETC, whereas larger values of the scale parameter of that distribution, the quality loss cost in the in-control state, the preventive maintenance cost, the reactive maintenance cost, the setup cost, and the inventory holding cost per unit time lead to the higher ETC values.

As future research, it is suggested to investigate other monitoring charts reviewed by Thaga and Sivasamy [9] for similar models. Designing attribute control charts with different sampling schemes, similar to [59], can be extended under the integrated model. Uncertainty in the model can be treated using a robust optimization approach applied in [54] and [60]. Recently, the ARMA control chart was applied to a ten-scenario model [61]. For the time being, we are trying to extend the acceptance control chart (ACC) for autocorrelated processes.

\section{Acknowledgments}

The author would like to acknowledge editors and reviewers of the paper for their important guiding and comments. This work was supported by the Iran National Science Foundation (INSF) [grant number 97015328].

\section{References}

[1] Cheng, L., Tsou, C.-S. and Yang, D.-Y. "Cost-service tradeoff analysis of reorder-point-lot-size inventory models", J. Manuf. Syst., 37, pp. 217-226 (2015).

[2] Zhou, X., Wu, C., Li, Y. et al. "A preventive maintenance model for leased equipment subject to internal degradation and external shock damage", Reliab. Eng. Syst. Saf., 154, pp. 1-7 (2016).

[3] Lee, P.-H., Torng, C.-C. and Liao, L.-F. "An economic design of combined double sampling and variable sampling interval $\mathrm{X}^{-}$control chart", Int. J. Prod. Econ., 138(1), pp. 102-106 (2012).

[4] Woodall, W.H. and Montgomery, D.C. "Some Current Directions in the Theory and Application of Statistical Process Monitoring", J. Qual. Technol., 46(1), pp. 78-94 (2014).

[5] Jafarian-Namin, S., Goli, A., Qolipour, M. et al. "Forecasting the wind power generation using Box-Jenkins and hybrid artificial intelligence: A case study", Int. J. Energy Sect. Manag., 13(4), pp. 1038-1062 (2019).

[6] Triantafyllopoulos, K. and Bersimis, S. "Phase II control charts for autocorrelated processes", Qual. Technol. Quant. Manag., 13(1), pp. 88-108 (2016). 
[7] Alwan, L.C. and Roberts, H.V. "The Problem of Misplaced Control Limits", J. R. Stat. Soc. C-Appl., 44(3), pp. 269-278 (1995).

[8] Psarakis, S. and Papaleonida, G.E.A. "SPC Procedures for Monitoring Autocorrelated Processes", Qual. Technol. Quant. Manag., 4(4), pp. 501-540 (2007).

[9] Thaga, K. and Sivasamy, R. "Single Variables Control Charts: A Further Overview", Indian J. Sci. Technol, 8, pp. 518-528 (2015).

[10] Alwan, L.C. and Roberts, H.V. "Time-Series Modeling for Statistical Process Control", J. Bus. Econ. Stat., 6(1), pp. 87-95 (1988).

[11] Vasilopoulos, A.V. and Stamboulis, A.P. "Modification of Control Chart Limits in the Presence of Data Correlation", J. Qual. Technol., 10(1), pp. 20-30 (1978).

[12] Karaoglan, A.D. "Control chart for autocorrelated processes: a review", Eng. Sci., 5, pp. 243-259 (2010).

[13] Osei-Aning, R., Abbasi, S.A. and Riaz, M. "Monitoring of serially correlated processes using residual control charts", Sci. Iran., 24(3), pp. 1603-1614 (2017).

[14] Chen, S. and Yu, J. "Deep recurrent neural network-based residual control chart for autocorrelated processes", Qual. Reliab. Eng. Int., 35(8), pp. 2687-2708 (2019).

[15] Wang, F.-K. and Cheng, X.-B. "Exponentially weighted moving average chart with a likelihood ratio test for monitoring autocorrelated processes", Qual. Reliab. Eng. Int., 36(2), pp. 753-764 (2020).

[16] Jiang, W., Tsui, K. and Woodall, W.H. "A New SPC Monitoring Method: The ARMA Chart", Technometrics, 42(4), pp. 399-410 (2000).

[17] Zhang, N.F. "A Statistical Control Chart for Stationary Process Data", Technometrics, 40(1), pp. 24-38 (1998).

[18] Wardell, D.G., Moskowitz, H. and Plante, R.D. "Control Charts in the Presence of Data Correlation", Manage. Sci., 38(8), pp. 1084-1105 (1992).

[19] Low, C. and Lin, W.Y. "Consideration of weibull distribution under the assignable causes for economic design of the ARMA control chart", J. Qual., 17(5), pp. 365-387 (2010).

[20] Lin, S.-N., Chou, C.-Y., Wang, S.-L. et al. "Economic design of autoregressive moving average control chart using genetic algorithms", Expert Syst. Appl., 39(2), pp. 1793-1798 (2012).

[21] Costa, A. and Fichera, S. "Economic statistical design of ARMA control chart through a Modified Fitness-based Self-Adaptive Differential Evolution", Comput. Ind. Eng., 105, pp. 174-189 (2017).

[22] Costa, A. and Fichera, S. "Economic-statistical design of adaptive arma control chart for autocorrelated data", J. Stat. Comput. Simul., 91(3), pp. 623-647 (2021).

[23] Ben-Daya, M. "The economic production lot-sizing problem with imperfect production processes and imperfect maintenance", Int. J. Prod. Econ., 76(3), pp. 257-264 (2002). 
[24] Hadidi, L.A., Al-Turki, U.M. and Rahim, A. "Integrated models in production planning and scheduling, maintenance and quality: a review", Int. J. Ind. Syst. Eng., 10(1), pp. 21-50 (2012).

[25] Rahim, M.A. "Joint determination of production quantity, inspection schedule, and control chart design", IIE Trans., 26(6), pp. 2-11 (1994).

[26] Rahim, M.A. and Ben-Daya, M. "A generalized economic model for joint determination of production run, inspection schedule and control chart design", Int. J. Prod. Res., 36(1), pp. 277-289 (1998).

[27] Rahim, M.A. and Ohta, H. "An integrated economic model for inventory and quality control problems", Eng. Optim., 37(1), pp. 65-81 (2005).

[28] Cheng, J.-C. and Chou, C.-Y. "A real-time inventory decision system using Western Electric run rules and ARMA control chart", Expert Syst. Appl., 35(3), pp. 755-761 (2008).

[29] Pan, E., Jin, Y. and Wang, Y. "Integration of economic production quantity in optimization design of control chart based on loss function and random process shift", J. Manuf. Technol. Manag., 22(7), pp. 929-946 (2011).

[30] Gunay, E.E. and Kula, U. "Integration of production quantity and control chart design in automotive manufacturing", Comput. Ind. Eng., 102, pp. 374-382 (2016).

[31] Tagaras, G. "An Integrated Cost Model for the Joint Optimization of Process Control and Maintenance", J. Oper. Res. Soc., 39(8), pp. 757-766 (1988).

[32] Ben-Daya, M. and Rahim, M.A. "Effect of maintenance on the economic design of X̄-control chart", Eur. J. Oper. Res., 120(1), pp. 131-143 (2000).

[33] Wu, J. and Makis, V. "Economic and economic-statistical design of a chi-square chart for CBM", Eur. J. Oper. Res., 188(2), pp. 516-529 (2008).

[34] Zhou, W.-H. and Zhu, G.-L. "Economic design of integrated model of control chart and maintenance management", Math. Comput. Modell., 47(11), pp. 1389-1395 (2008).

[35] Panagiotidou, S. and Nenes, G. "An economically designed, integrated quality and maintenance model using an adaptive Shewhart chart", Reliab. Eng. Syst. Saf., 94(3), pp. 732-741 (2009).

[36] Yin, Z. and Makis, V. "Economic and economic-statistical design of a multivariate Bayesian control chart for condition-based maintenance", IMA J. Manage. Math., 22(1), pp. 47-63 (2010).

[37] Ho, L.L. and Quinino, R.C. "Integrating on-line process control and imperfect corrective maintenance: An economical design", Eur. J. Oper. Res., 222(2), pp. 253-262 (2012).

[38] Xiang, Y. "Joint optimization of $\mathrm{X}^{-}$control chart and preventive maintenance policies: A discrete-time Markov chain approach", Eur. J. Oper. Res., 229(2), pp. 382-390 (2013).

[39] Yin, H., Zhang, G., Zhu, H., et al. "An integrated model of statistical process control and maintenance based on the delayed monitoring", Reliab. Eng. Syst. Saf., 133, pp. 323-333 (2015). 
[40] Abouei Ardakan, M., Zeinal Hamadani, A., Sima, M. et al. "A hybrid model for economic design of MEWMA control chart under maintenance policies", Int. J. Adv. Manuf. Technol., 83(9), pp. 2101-2110 (2016).

[41] Rasay, H., Fallahnezhad, M.S. and Zare Mehrjerdi, Y. "An integrated model for economic design of chi-square control chart and maintenance planning", Commun. Stat.-Theor. M., 47(12), pp. 2892-2907 (2018).

[42] Salmasnia, A., Namdar, M. and Abdzadeh, B. "An integrated quality and maintenance model for two-unit series systems", Commun. Stat.-Simul. Comput., 49(4), pp. 886-917 (2020).

[43] Salmasnia, A., Abdzadeh, B. and Rahimi, A. "Joint optimisation of double warning T2-Hotelling chart and maintenance policy with multiple assignable causes", J. Stat. Comput. Simul., 90(3), pp. 465-488 (2020).

[44] Farahani, A. and Tohidi, H. "Integrated optimization of quality and maintenance: A literature review", Comput. Ind. Eng., 151, p. 106924 (2021).

[45] Ben-Daya, M. and Makhdoum, M. "Integrated Production and Quality Model under Various Preventive Maintenance Policies", J. Oper. Res. Soc., 49(8), pp. 840-853 (1998).

[46] Lam, K.K. and Rahim, M.A. "A sensitivity analysis of an integrated model for joint determination of economic design of control charts, economic production quantity and production run length for a deteriorating production system", Qual. Reliab. Eng. Int., 18(4), pp. 305-320 (2002).

[47] Pan, E., Jin, Y., Wang, S. et al. "An integrated EPQ model based on a control chart for an imperfect production process", Int. J. Prod. Res., 50(23), pp. 6999-7011 (2012).

[48] Salmasnia, A., Abdzadeh, B. and Namdar, M. "A joint design of production run length, maintenance policy and control chart with multiple assignable causes", J. Manuf. Syst., 42, pp. 44-56 (2017).

[49] Salmasnia, A., Kaveie, M. and Namdar, M. "An integrated production and maintenance planning model under VP-T2 Hotelling chart", Comput. Ind. Eng., 118, pp. 89-103 (2018).

[50] Salmasnia, A., Hajihosseini, Z., Namdar, M. et al. "A joint determination of production cycle length, maintenance policy, and control chart parameters considering time value of money under stochastic shift size", Sci. Iran., 27(1), pp. 427-447 (2020).

[51] Salmasnia, A., Soltani, F., Heydari, E. et al. "An integrated model for joint determination of production run length, adaptive control chart parameters and maintenance policy", J. Ind. Prod. Eng., 36(6), pp. 401-417 (2019).

[52] Salmasnia, A., Soltany, F., Noroozi, M. et al. "An economic-statistical model for production and maintenance planning under adaptive non-central chi-square control chart", J. Ind. Syst. Eng., 12, pp. 35-65 (2019).

[53] Niaki, S.T.A., Toosheghanian, M. and Gazaneh, F.M. "Economic design of VSI $\bar{X}$ control chart with correlated non-normal data under multiple assignable causes", J. Stat. Comput. Simul., 83(7), pp. 1279-1300 (2013). 
[54] Jafarian-Namin, S., Fallahnezhad, M.S., Tavakkoli-Moghaddam, R. et al. "Robust Economic-Statistical Design of Acceptance Control Chart", Journal of Quality Engineering and Production Optimization, 4(1), pp. 55-72 (2019).

[55] Kennedy, J. and Eberhart, R. "Particle swarm optimization", Proceedings of ICNN'95 - Int. Conf. on Neural Networks, 4, Perth, WA, Australia, pp. 1942-1948 (1995).

[56] Chih, M., Yeh, L.-L. and Li, F.-C. (2011), "Particle swarm optimization for the economic and economic statistical designs of the $\mathrm{X}^{-}$control chart", Appl. Soft Comput., 11(8), pp. 5053-5067.

[57] Morabi, Z.S., Owlia, M.S., Bashiri, M. et al. "Multi-objective design of $\mathrm{X}^{-}$control charts with fuzzy process parameters using the hybrid epsilon constraint PSO", Appl. Soft Comput., 30, pp. 390-399 (2015).

[58] Salmasnia, A., Namdar, M. and Noroozi, M. "Robust design of a VP-NCS chart for joint monitoring mean and variability in series systems under maintenance policy", Comput. Ind. Eng., 124, pp. 220-236 (2018).

[59] Shojaee, M., Jafarian Namin, S., Fatemi Ghomi, S.M.T. et al. "Applying SVSSI sampling scheme on np-chart to Decrease the Time of Detecting Shifts - Markov chain approach, and Monte Carlo simulation", Sci. Iran., pp. 1-30 (2020). DOI: 10.24200/sci.2020.52677.2833.

[60] Jafarian-Namin, S., Fallahnezhad, M.S., Tavakkoli-Moghaddam, R. et al. "Robust modeling of acceptance control chart to specify best design parameters", In Studies in Fuzziness and Soft Computing, Shabazova, S., Kacprzyk J., Balas V. and Kreinovich V., Eds., pp. 321-332, Springer, Switzerland (2021).

[61] Jafarian-Namin, S., Fallahnezhad, M.S., Tavakkoli-Moghaddam, R. et al. "An integrated quality, maintenance and production model based on the delayed monitoring under the ARMA control chart", J. Stat. Comput. Simul., pp. 1-25 (2021). DOI: 10.1080/00949655.2021.1904241.

\section{Biographies}

Samrad Jafarian-Namin holds Ph.D. degree in Industrial Engineering from Yazd University, Iran. He collaborated as visiting scholar in Amirkabir University of Technology. He has granted for Ph.D. Thesis by Iran National Science Foundation (INSF) and as a talented student by Iran National Elites Foundation (INEF). His research interests include statistical process control, time series analysis, reliability engineering and generally implementation of six sigma methodology in application.

Mohammad Saber Fallah Nezhad is currently an Associate Professor of Industrial Engineering at Yazd University. He received his BS, MS, and PhD degrees in Industrial Engineering from Sharif University of Technology in 2003, 2005, and 2008, respectively. His research interests include quality control, Bayesian inference, dynamic programming, and Markov models.

Reza Tavakkoli-Moghaddam is the professor of Industrial Engineering at College of Engineering, University of Tehran in Iran. He obtained his B.Sc., M.Sc. and Ph.D. from Iran University of Science and Technology in Tehran (1989), University of Melbourne in 
Melbourne (1994), and Swinburne University of Technology in Melbourne (1998), respectively. He serves as the Editor-in-Chief of two journals and the Editorial Board of five journals. He was the recipient of the 2009 and 2011 Distinguished Researcher Awards as well as the 2010 and 2014 Distinguished Applied Research Awards by University of Tehran in Iran. He was also selected as National Iranian Distinguished Researcher in 2008 and 2010 by the Ministry of Science, Research, and Technology (MSRT) in Iran. He obtained the outstanding rank as the top 1\% scientist and researcher in the world elite group, reported by Thomson Reuters in 2014. Professor Tavakkoli-Moghaddam has published 5 books, 24 book chapters, more than 1000 papers in reputable academic journals and conferences.

Ali Salmasnia is currently an Associate Professor in University of Qom, Qom, Iran. His research interests include quality engineering, reliability, applied multivariate statistics and multi-criterion decision making. He is the author or co-author of various papers published in Computers \& Industrial Engineering, Journal of Manufacturing Systems, Applied Soft Computing, Neurocomputing, Applied Mathematical Modelling, Expert Systems with Applications, Applied Stochastic Models in Business and Industry, IEEE Transactions on Engineering Management, International Journal of Information Technology and Decision Making, TOP, Quality and Reliability Engineering International, Communications in Statistics-Simulation and Computation, Operational Research, International Journal of Advanced Manufacturing Technology, and Scientia Iranica.

Mohammad Hossein Abooie is currently an Assistant Professor of Industrial Engineering at Yazd University. He received his BS, MS, and PhD degrees in Industrial Engineering from Amir Kabir University of Technology in 1993, 1995, and 2009, respectively. His research interests include quality control and management, customer relationship management and marketing, economics, and applied operations research. 


\section{Figures}

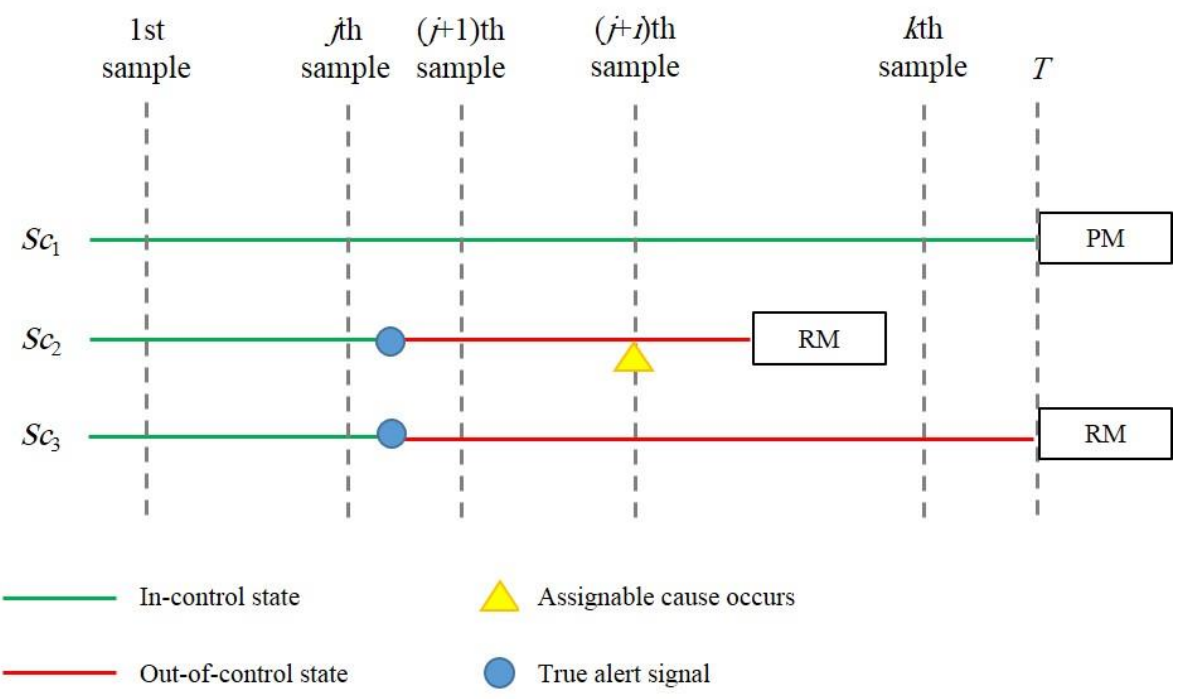

Figure 1. Graphical representation of scenarios

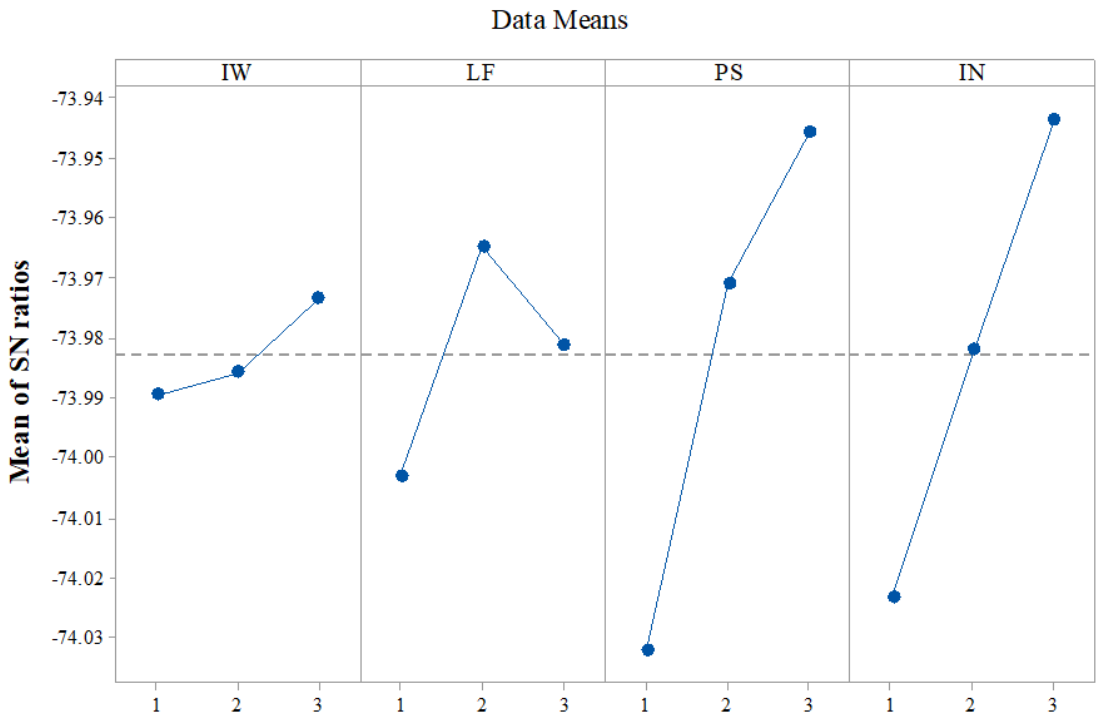

Figure 2. Main factors plot for $\mathrm{S} / \mathrm{N}$ ratios 


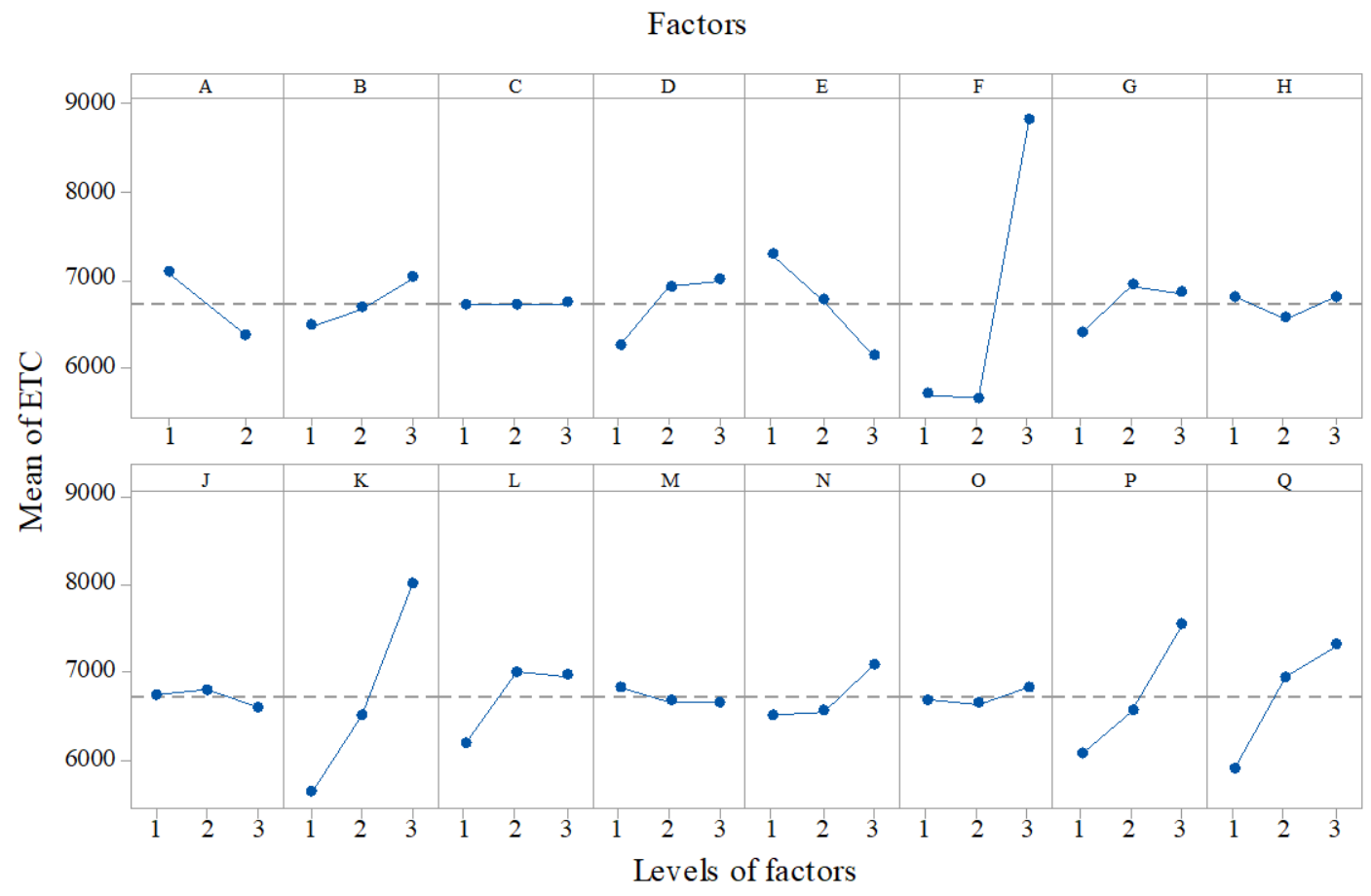

Figure 3. Main effects of sixteen independent factors on ETC

(a)

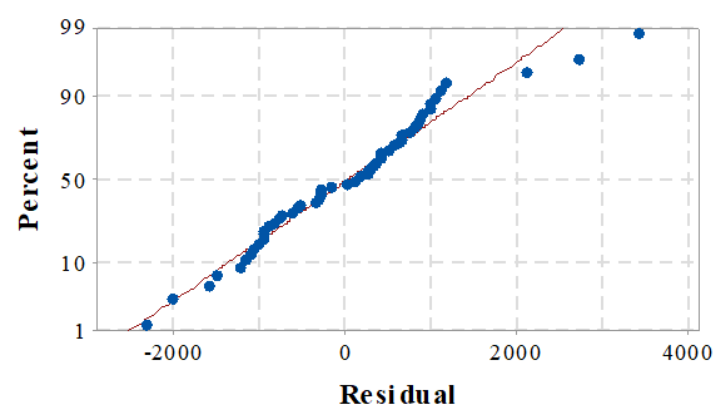

(c)

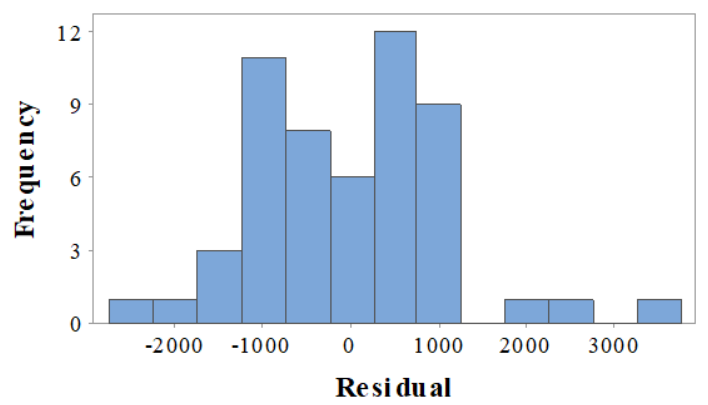

(b)

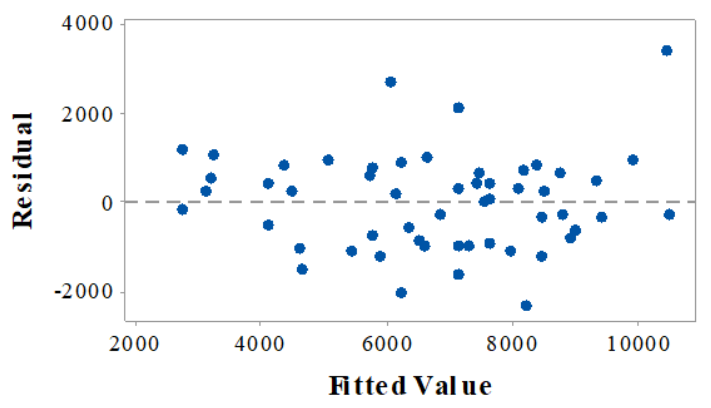

(d)

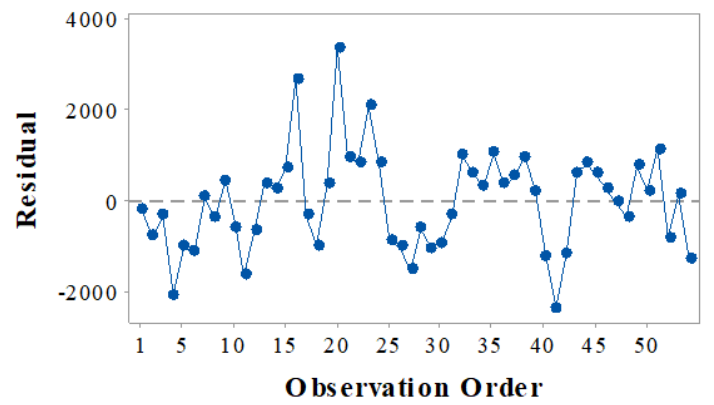

Figure 4. Residual plots: (a) Normal probability plot, (b) residuals versus fitted values, (c) histogram, and (d) residuals versus observation order 


\section{Tables}

Table 1. Summarized literature review.

\begin{tabular}{|c|c|c|c|c|c|c|c|}
\hline \multirow[t]{2}{*}{ Paper } & \multicolumn{3}{|c|}{ Integrated concepts } & \multicolumn{2}{|c|}{ Design method } & \multicolumn{2}{|c|}{ Strucure of data } \\
\hline & $\stackrel{2}{3}$ & 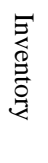 & 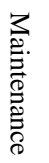 & $\mathbb{\Xi}$ & $\stackrel{\Pi}{\Theta}$ & 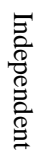 & $\begin{array}{l}\Omega \\
\stackrel{0}{0} \\
\stackrel{0}{\overrightarrow{0}} \\
\stackrel{0}{2}\end{array}$ \\
\hline Rahim [24] & $\checkmark$ & $\checkmark$ & - & $\checkmark$ & - & $\checkmark$ & - \\
\hline Rahim and Ben-Daya [25] & $\checkmark$ & $\checkmark$ & - & $\checkmark$ & - & $\checkmark$ & - \\
\hline Rahim and Ohta [26] & $\checkmark$ & $\checkmark$ & - & $\checkmark$ & - & $\checkmark$ & - \\
\hline Cheng and Chou [27] & $\checkmark$ & $\checkmark$ & - & $\checkmark$ & - & - & $\checkmark$ \\
\hline Pan et al. [28] & $\checkmark$ & $\checkmark$ & - & $\checkmark$ & - & $\checkmark$ & - \\
\hline Gunay and Kula [29] & $\checkmark$ & $\checkmark$ & - & $\checkmark$ & - & $\checkmark$ & - \\
\hline Tagaras [30] & $\checkmark$ & - & $\checkmark$ & $\checkmark$ & - & $\checkmark$ & - \\
\hline Ben-Daya and Rahim [31] & $\checkmark$ & - & $\checkmark$ & $\checkmark$ & - & $\checkmark$ & - \\
\hline $\mathrm{Wu}$ and Makis [32] & $\checkmark$ & - & $\checkmark$ & $\checkmark$ & $\checkmark$ & $\checkmark$ & - \\
\hline Zhou and Zhu [33] & $\checkmark$ & - & $\checkmark$ & $\checkmark$ & - & $\checkmark$ & - \\
\hline Panagiotidou and Nenes [34] & $\checkmark$ & - & $\checkmark$ & $\checkmark$ & - & $\checkmark$ & - \\
\hline Yin and Makis [35] & $\checkmark$ & - & $\checkmark$ & $\checkmark$ & $\checkmark$ & $\checkmark$ & - \\
\hline Ho and Quinino [36] & $\checkmark$ & - & $\checkmark$ & $\checkmark$ & - & $\checkmark$ & - \\
\hline Xiang [37] & $\checkmark$ & - & $\checkmark$ & $\checkmark$ & - & $\checkmark$ & - \\
\hline Yin et al. [38] & $\checkmark$ & - & $\checkmark$ & $\checkmark$ & - & $\checkmark$ & - \\
\hline Ardakan et al. [39] & $\checkmark$ & - & $\checkmark$ & $\checkmark$ & - & $\checkmark$ & - \\
\hline Rasay et al. [40] & $\checkmark$ & - & $\checkmark$ & $\checkmark$ & - & $\checkmark$ & - \\
\hline Salmasnia et al. [41] & $\checkmark$ & - & $\checkmark$ & - & $\checkmark$ & $\checkmark$ & - \\
\hline Salmasnia et al. [42] & $\checkmark$ & - & $\checkmark$ & - & $\checkmark$ & $\checkmark$ & - \\
\hline Ben-Daya and Makhdoum [43] & $\checkmark$ & $\checkmark$ & $\checkmark$ & $\checkmark$ & - & $\checkmark$ & - \\
\hline Lam and Rahim [44] & $\checkmark$ & $\checkmark$ & $\checkmark$ & $\checkmark$ & - & $\checkmark$ & - \\
\hline Pan et al. [45] & $\checkmark$ & $\checkmark$ & $\checkmark$ & - & $\checkmark$ & $\checkmark$ & - \\
\hline Salmasnia et al. [46] & $\checkmark$ & $\checkmark$ & $\checkmark$ & - & $\checkmark$ & $\checkmark$ & - \\
\hline Salmasnia et al. [47] & $\checkmark$ & $\checkmark$ & $\checkmark$ & - & $\checkmark$ & $\checkmark$ & - \\
\hline Salmasnia et al. [48] & $\checkmark$ & $\checkmark$ & $\checkmark$ & - & $\checkmark$ & $\checkmark$ & - \\
\hline Salmasnia et al. [49] & $\checkmark$ & $\checkmark$ & $\checkmark$ & - & $\checkmark$ & $\checkmark$ & - \\
\hline Salmasnia et al. [50] & $\checkmark$ & $\checkmark$ & $\checkmark$ & - & $\checkmark$ & $\checkmark$ & - \\
\hline This paper & $\checkmark$ & $\checkmark$ & $\checkmark$ & - & $\checkmark$ & - & $\checkmark$ \\
\hline
\end{tabular}

Table 2. Notations.

\begin{tabular}{|c|c|c|}
\hline Set & Notation & Description \\
\hline \multicolumn{3}{|l|}{ Decision variables } \\
\hline & $n$ & Sample size \\
\hline & $h$ & Sampling interval \\
\hline & $l$ & Control limit parameter \\
\hline & $k$ & Number of samplings in monitoring period \\
\hline & $\phi$ & Autoregressive parameter of ARMA chart \\
\hline & $\theta$ & Moving average parameter of ARMA chart \\
\hline \multicolumn{3}{|l|}{ Index \& indicator } \\
\hline & $i$ & Index of measurements in each column $(i=1, \ldots, M)$ \\
\hline & $j$ & Index of generated columns $(j=1, \ldots, S)$ \\
\hline & $r$ & Index of scenario $(r=1,2,3)$ \\
\hline & $t$ & Index of time \\
\hline & $y$ & Index of number of sampling intervals $(y=1, \ldots, k)$ \\
\hline \multicolumn{3}{|l|}{ Time parameters } \\
\hline & $E$ & Time to sample and chart one item \\
\hline & $E\left(T_{i n} \mid S c_{r}\right)$ & Expected value of in-control time under $r^{\text {th }}$ scenario \\
\hline & $E\left(T_{\text {out }} \mid S c_{r}\right)$ & Expected value of out-of-control time under $r^{\text {th }}$ scenario \\
\hline & $f(t \mid(k+1) h)$ & Probability density function of truncated Weibull distibution \\
\hline & $F(t)$ & Cumulative function of truncated Weibull distibution \\
\hline & $T$ & Process cycle time \\
\hline & $T_{1}$ & Time to detect the assignable cause \\
\hline & $T_{\text {in }}$ & In-control time \\
\hline & $T_{\text {out }}$ & Out-of-control time \\
\hline & $\gamma$ & Shape parameter of truncated Weibull distibution \\
\hline & $\lambda$ & Scale parameter of truncated Weibull distibution \\
\hline
\end{tabular}




\begin{tabular}{|c|c|c|}
\hline \multicolumn{3}{|l|}{ Cost parameters } \\
\hline & $A$ & Set up cost per production \\
\hline & $B$ & Inventory holding cost per unit per time unit \\
\hline & $C_{f}$ & Fixed cost of sampling \\
\hline & $C_{i n}$ & Quality loss cost during in-control state \\
\hline & $C_{\text {out }}$ & Quality loss cost during out-of-control state \\
\hline & $C_{p m}$ & Preventive maintenance cost \\
\hline & $C_{r m}$ & Reactive maintenance cost \\
\hline & $C_{v}$ & Variable cost of sampling \\
\hline & $C_{Y}$ & Cost of false alarm inspection \\
\hline & $E\left(C_{M} \mid S c_{r}\right)$ & Expected maintenance cost for each scenario \\
\hline & $E\left(C_{Q} \mid S c_{r}\right)$ & Expected quality loss cost for each scenario \\
\hline & $E\left(C_{S} \mid S c_{r}\right)$ & Expected sampling cost per cycle time for each scenario \\
\hline & $E(I)$ & Expected summation of inventory holding and ordering costs \\
\hline & $E(M)$ & Expected maintenance cost \\
\hline & $E(Q)$ & Expected quality loss cost \\
\hline & $E(S)$ & Expected sampling cost \\
\hline & ETC & Expected total cost \\
\hline & $I H C$ & Inventory holding cost \\
\hline & $S U C$ & Set up cost \\
\hline \multicolumn{3}{|c|}{ Process parameters } \\
\hline & $a_{t}$ & Noise factor (independent, identically distributed (iid) process) \\
\hline & $A R L_{0}$ & Average run length during in-control period \\
\hline & $A R L_{1}$ & Average run length during out-of-control period \\
\hline & $d$ & Daily demand rate \\
\hline & $D$ & Annual demand rate \\
\hline & $L C L$ & Lower control limit of ARMA chart \\
\hline & $p$ & Production rate \\
\hline & $\operatorname{Pr}\left(S c_{r}\right)$ & Occurrence probability of $r^{\text {th }}$ scenario \\
\hline & $Q$ & Economic production quantity \\
\hline & $s_{r}$ & Expected number of samplings in the in-control state under $r^{\text {th }}$ scenario \\
\hline & $u$ & Autoregressive coefficient of underlying process \\
\hline & $U C L$ & Upper control limit of ARMA chart \\
\hline & $v$ & Moving average coefficient of underlying process \\
\hline & $X_{t}$ & Variable of underlying process \\
\hline & $Z_{t}$ & ARMA statistic corresponding to $X_{t}$ \\
\hline & $\alpha$ & Probability of false alarm or Type I error \\
\hline & $\beta$ & Probability of Type II error \\
\hline & $\delta$ & Magnitude of shift in process mean \\
\hline & $\mu_{0}$ & Mean of ARMA sample statistic in state 0 \\
\hline & $\mu_{1}$ & Shifted mean value in state 1 \\
\hline & $\sigma_{a}$ & Standard deviation of noise factor \\
\hline & $\sigma_{X}$ & Standard deviation of underlying process \\
\hline & $\sigma_{Z}$ & Standard deviation of ARMA sample statistic \\
\hline
\end{tabular}

Table 3. Values of the parameters in the numerical example

\begin{tabular}{lccccccc}
\hline Parameter & $\mu$ & $\sigma_{x}{ }^{2}$ & $u$ & $v$ & $\delta$ & $\lambda$ & $\gamma$ \\
\hline Value & 100 & 10 & 0.475 & 0.00 & 2 & 0.01 & 1 \\
\hline Parameter & $C_{\text {in }}$ & $C_{\text {out }}$ & $C_{f}$ & $C_{v}$ & $C_{Y}$ & $C_{p m}$ & $C_{r m}$ \\
\hline Value & 115 & 950 & 1 & 0.2 & 200 & 2400 & 5000 \\
\hline Parameter & $E$ & $T_{1}$ & $p$ & $d$ & $D$ & $A$ & $B$ \\
\hline Value & 0.01 & 1 & 100 & 80 & 10000 & 60 & 10 \\
\hline
\end{tabular}


Table 4. Calibration of PSO: plan of factors and levels adapted from Chih et al. (2011)

\begin{tabular}{lccc} 
Factor & Level 1 & Level 2 & Level 3 \\
\hline$w$ & 0.8 & 1 & 1.2 \\
$\left(c_{1}, c_{2}\right)$ & $(1.5,2.5)$ & $(2.0,2.0)$ & $(2.5,1.5)$ \\
$N$ & 20 & 50 & 80 \\
$m$ & 50 & 100 & 150 \\
\hline
\end{tabular}

Table 5. Experimental design of $\mathrm{L}_{9}$ orthogonal array for PSO factors

\begin{tabular}{lccccc}
\hline Trial & $w$ & $\left(c_{1}, c_{2}\right)$ & $N$ & $m$ & $\mathrm{~S} / \mathrm{N}$ \\
\hline 1 & 1 & 1 & 1 & 1 & -74.0990 \\
\hline 2 & 1 & 2 & 2 & 2 & -73.9585 \\
\hline 3 & 1 & 3 & 3 & 3 & -73.9114 \\
\hline 4 & 2 & 1 & 2 & 3 & -73.9548 \\
\hline 5 & 2 & 2 & 3 & 1 & -73.9706 \\
\hline 6 & 2 & 3 & 1 & 2 & -74.0323 \\
\hline 7 & 3 & 1 & 3 & 2 & -73.9554 \\
\hline 8 & 3 & 2 & 1 & 3 & -73.9654 \\
\hline 9 & 3 & 3 & 2 & 1 & -73.9998 \\
\hline
\end{tabular}

Table 6. S/N ratios for different levels of PSO factors (the best level for each factor was bolded)

\begin{tabular}{lccc}
\hline Factor & Level 1 & Level 2 & Level 3 \\
\hline$w$ & -73.99 & -73.99 & $\mathbf{- 7 3 . 9 7}$ \\
$\left(c_{1}, c_{2}\right)$ & -74.00 & $\mathbf{- 7 3 . 9 6}$ & -73.98 \\
$N$ & -74.03 & -73.97 & $\mathbf{- 7 3 . 9 5}$ \\
$m$ & -74.02 & -73.98 & $\mathbf{- 7 3 . 9 4}$ \\
\hline
\end{tabular}

Table 7. Comparison between integrated-QIM and joint-QIM models

\begin{tabular}{cccccccc}
\hline Model & $\mathrm{E}(\mathrm{Q})$ & $\mathrm{E}(\mathrm{S})$ & $\mathrm{E}(\mathrm{M})$ & $\mathrm{E}(\mathrm{I})$ & $E T C$ & $A R L_{0}$ & $A R L_{1}$ \\
\hline Integrated-QIM & 690.63 & 26.28 & 2547.59 & 1669.63 & 4934.12 & 279.12 & 5.02 \\
Joint-QIM & 1236.75 & 5.31 & 2595.86 & 1549.19 & 5387.12 & 212.44 & 6.27 \\
\hline
\end{tabular}


Table 8. Comparison between integrated and joint models by considering different ARMA parameters

\begin{tabular}{|c|c|c|c|c|}
\hline \multicolumn{2}{|c|}{ ARMA Parameters } & \multicolumn{2}{|c|}{$E T C$} & \multirow{2}{*}{ Cost Saving } \\
\hline$u$ & $v$ & Joint-QIM Model & Integrated-QIM Model & \\
\hline \multirow[t]{4}{*}{0.00} & 0.00 & 5195.48 & 4909.58 & 285.90 \\
\hline & 0.25 & 5179.58 & 4900.18 & 279.40 \\
\hline & 0.50 & 5169.65 & 4896.91 & 272.74 \\
\hline & 0.75 & 5159.44 & 4890.90 & 268.54 \\
\hline \multirow[t]{4}{*}{0.25} & 0.00 & 5208.04 & 4922.18 & 285.86 \\
\hline & 0.25 & 5192.36 & 4912.05 & 280.31 \\
\hline & 0.50 & 5177.88 & 4899.11 & 278.77 \\
\hline & 0.75 & 5169.26 & 4894.53 & 274.73 \\
\hline \multirow[t]{4}{*}{0.50} & 0.00 & 5378.22 & 4936.36 & 441.86 \\
\hline & 0.25 & 5368.91 & 4923.15 & 445.76 \\
\hline & 0.50 & 5196.26 & 4909.78 & 286.48 \\
\hline & 0.75 & 5176.31 & 4903.75 & 272.56 \\
\hline \multirow[t]{4}{*}{0.75} & 0.00 & 5388.57 & 5055.66 & 332.91 \\
\hline & 0.25 & 5382.90 & 4957.23 & 425.67 \\
\hline & 0.50 & 5372.82 & 4940.58 & 432.24 \\
\hline & 0.75 & 5195.48 & 4910.47 & 285.01 \\
\hline
\end{tabular}

Table 9. Comparison among various control charts using ETC values of the integrated-QIM model

\begin{tabular}{cccccc}
\multicolumn{2}{c}{ ARMA Parameters } & & \multicolumn{3}{c}{ Control Charts } \\
\cline { 1 - 2 } \cline { 5 - 6 }$u$ & $v$ & & SCC & EWMAST & ARMA \\
\hline-0.950 & 0.000 & & 4902.24 & 4888.26 & $\mathbf{4 8 8 4 . 4 9}$ \\
-0.475 & 0.000 & & 4927.20 & 4902.41 & $\mathbf{4 8 9 6 . 4 3}$ \\
0.475 & 0.000 & & 5031.38 & 4941.31 & $\mathbf{4 9 3 8 . 0 7}$ \\
0.950 & 0.000 & & 5153.89 & 5118.12 & $\mathbf{5 0 7 6 . 9 9}$ \\
0.475 & -0.900 & & 5014.58 & 4956.94 & $\mathbf{4 9 5 2 . 3 5}$ \\
0.950 & 0.450 & & 5186.57 & 5026.22 & $\mathbf{4 9 8 8 . 0 5}$ \\
0.950 & -0.900 & & 5802.70 & 5035.80 & $\mathbf{4 9 9 9 . 6 5}$ \\
\hline
\end{tabular}

Table 10. Levels plan of factors for the sensitivity analysis

\begin{tabular}{lcccccccc}
\hline Factor & $\mathrm{A}$ & $\mathrm{B}$ & $\mathrm{C}$ & $\mathrm{D}$ & $\mathrm{E}$ & $\mathrm{F}$ & $\mathrm{G}$ & $\mathrm{H}$ \\
\hline Notation & $\delta$ & $u$ & $v$ & $\lambda$ & $\gamma$ & $C_{\text {in }}$ & $C_{\text {out }}$ & $C_{f}$ \\
\hline Level 1 & 1 & 0.00 & 0.00 & 0.01 & 0.5 & 50 & 100 & 0.5 \\
\hline Level 2 & 4 & 0.25 & 0.25 & 0.03 & 1.0 & 115 & 950 & 1.0 \\
\hline Level 3 & - & 0.75 & 0.75 & 0.05 & 2.0 & 700 & 1500 & 4.0 \\
\hline Factor & $\mathrm{J}$ & $\mathrm{K}$ & $\mathrm{L}$ & $\mathrm{M}$ & $\mathrm{N}$ & $\mathrm{O}$ & $\mathrm{P}$ & $\mathrm{Q}$ \\
\hline Notation & $C_{v}$ & $C_{p m}$ & $C_{r m}$ & $C_{y}$ & $E$ & $T_{1}$ & $A$ & $B$ \\
\hline Level 1 & 0.2 & 1000 & 2500 & 50 & 0.01 & 0.1 & 30 & 5 \\
\hline Level 2 & 0.5 & 2400 & 5000 & 200 & 0.05 & 1 & 60 & 10 \\
\hline Level 3 & 2.0 & 4000 & 7500 & 500 & 0.20 & 2 & 120 & 20 \\
\hline
\end{tabular}


Table 11. Levels of factors for generated trials with the Taguchi L54 design

\begin{tabular}{|c|c|c|c|c|c|c|c|c|c|c|c|c|c|c|c|c|}
\hline Trial & A & B & C & $\mathrm{D}$ & $\mathrm{E}$ & $\mathrm{F}$ & $\mathrm{G}$ & $\mathrm{H}$ & $\mathrm{J}$ & $\mathrm{K}$ & $\mathrm{L}$ & $\mathrm{M}$ & $\mathrm{N}$ & $\mathrm{O}$ & $\mathrm{P}$ & Q \\
\hline 1 & 1 & 1 & 1 & 1 & 1 & 1 & 1 & 1 & 1 & 1 & 1 & 1 & 1 & 1 & 1 & 1 \\
\hline 2 & 1 & 1 & 1 & 1 & 1 & 1 & 1 & 1 & 2 & 2 & 2 & 2 & 2 & 2 & 2 & 2 \\
\hline 3 & 1 & 1 & 1 & 1 & 1 & 1 & 1 & 1 & 3 & 3 & 3 & 3 & 3 & 3 & 3 & 3 \\
\hline 4 & 1 & 1 & 2 & 2 & 2 & 2 & 2 & 2 & 1 & 1 & 1 & 1 & 1 & 1 & 2 & 3 \\
\hline 5 & 1 & 1 & 2 & 2 & 2 & 2 & 2 & 2 & 2 & 2 & 2 & 2 & 2 & 2 & 3 & 1 \\
\hline 6 & 1 & 1 & 2 & 2 & 2 & 2 & 2 & 2 & 3 & 3 & 3 & 3 & 3 & 3 & 1 & 2 \\
\hline 7 & 1 & 1 & 3 & 3 & 3 & 3 & 3 & 3 & 1 & 1 & 1 & 1 & 1 & 1 & 3 & 2 \\
\hline 8 & 1 & 1 & 3 & 3 & 3 & 3 & 3 & 3 & 2 & 2 & 2 & 2 & 2 & 2 & 1 & 3 \\
\hline 9 & 1 & 1 & 3 & 3 & 3 & 3 & 3 & 3 & 3 & 3 & 3 & 3 & 3 & 3 & 2 & 1 \\
\hline 10 & 1 & 2 & 1 & 1 & 2 & 2 & 3 & 3 & 1 & 1 & 2 & 2 & 3 & 3 & 1 & 1 \\
\hline 11 & 1 & 2 & 1 & 1 & 2 & 2 & 3 & 3 & 2 & 2 & 3 & 3 & 1 & 1 & 2 & 2 \\
\hline 12 & 1 & 2 & 1 & 1 & 2 & 2 & 3 & 3 & 3 & 3 & 1 & 1 & 2 & 2 & 3 & 3 \\
\hline 13 & 1 & 2 & 2 & 2 & 3 & 3 & 1 & 1 & 1 & 1 & 2 & 2 & 3 & 3 & 2 & 3 \\
\hline 14 & 1 & 2 & 2 & 2 & 3 & 3 & 1 & 1 & 2 & 2 & 3 & 3 & 1 & 1 & 3 & 1 \\
\hline 15 & 1 & 2 & 2 & 2 & 3 & 3 & 1 & 1 & 3 & 3 & 1 & 1 & 2 & 2 & 1 & 2 \\
\hline 16 & 1 & 2 & 3 & 3 & 1 & 1 & 2 & 2 & 1 & 1 & 2 & 2 & 3 & 3 & 3 & 2 \\
\hline 17 & 1 & 2 & 3 & 3 & 1 & 1 & 2 & 2 & 2 & 2 & 3 & 3 & 1 & 1 & 1 & 3 \\
\hline 18 & 1 & 2 & 3 & 3 & 1 & 1 & 2 & 2 & 3 & 3 & 1 & 1 & 2 & 2 & 2 & 1 \\
\hline 19 & 1 & 3 & 1 & 2 & 1 & 3 & 2 & 3 & 1 & 2 & 1 & 3 & 2 & 3 & 1 & 1 \\
\hline 20 & 1 & 3 & 1 & 2 & 1 & 3 & 2 & 3 & 2 & 3 & 2 & 1 & 3 & 1 & 2 & 2 \\
\hline 21 & 1 & 3 & 1 & 2 & 1 & 3 & 2 & 3 & 3 & 1 & 3 & 2 & 1 & 2 & 3 & 3 \\
\hline 22 & 1 & 3 & 2 & 3 & 2 & 1 & 3 & 1 & 1 & 2 & 1 & 3 & 2 & 3 & 2 & 3 \\
\hline 23 & 1 & 3 & 2 & 3 & 2 & 1 & 3 & 1 & 2 & 3 & 2 & 1 & 3 & 1 & 3 & 1 \\
\hline 24 & 1 & 3 & 2 & 3 & 2 & 1 & 3 & 1 & 3 & 1 & 3 & 2 & 1 & 2 & 1 & 2 \\
\hline 25 & 1 & 3 & 3 & 1 & 3 & 2 & 1 & 2 & 1 & 2 & 1 & 3 & 2 & 3 & 3 & 2 \\
\hline 26 & 1 & 3 & 3 & 1 & 3 & 2 & 1 & 2 & 2 & 3 & 2 & 1 & 3 & 1 & 1 & 3 \\
\hline 27 & 1 & 3 & 3 & 1 & 3 & 2 & 1 & 2 & 3 & 1 & 3 & 2 & 1 & 2 & 2 & 1 \\
\hline 28 & 2 & 1 & 1 & 3 & 3 & 2 & 2 & 1 & 1 & 3 & 3 & 2 & 2 & 1 & 1 & 1 \\
\hline 29 & 2 & 1 & 1 & 3 & 3 & 2 & 2 & 1 & 2 & 1 & 1 & 3 & 3 & 2 & 2 & 2 \\
\hline 30 & 2 & 1 & 1 & 3 & 3 & 2 & 2 & 1 & 3 & 2 & 2 & 1 & 1 & 3 & 3 & 3 \\
\hline 31 & 2 & 1 & 2 & 1 & 1 & 3 & 3 & 2 & 1 & 3 & 3 & 2 & 2 & 1 & 2 & 3 \\
\hline 32 & 2 & 1 & 2 & 1 & 1 & 3 & 3 & 2 & 2 & 1 & 1 & 3 & 3 & 2 & 3 & 1 \\
\hline 33 & 2 & 1 & 2 & 1 & 1 & 3 & 3 & 2 & 3 & 2 & 2 & 1 & 1 & 3 & 1 & 2 \\
\hline 34 & 2 & 1 & 3 & 2 & 2 & 1 & 1 & 3 & 1 & 3 & 3 & 2 & 2 & 1 & 3 & 2 \\
\hline 35 & 2 & 1 & 3 & 2 & 2 & 1 & 1 & 3 & 2 & 1 & 1 & 3 & 3 & 2 & 1 & 3 \\
\hline 36 & 2 & 1 & 3 & 2 & 2 & 1 & 1 & 3 & 3 & 2 & 2 & 1 & 1 & 3 & 2 & 1 \\
\hline 37 & 2 & 2 & 1 & 2 & 3 & 1 & 3 & 2 & 1 & 2 & 3 & 1 & 3 & 2 & 1 & 1 \\
\hline 38 & 2 & 2 & 1 & 2 & 3 & 1 & 3 & 2 & 2 & 3 & 1 & 2 & 1 & 3 & 2 & 2 \\
\hline 39 & 2 & 2 & 1 & 2 & 3 & 1 & 3 & 2 & 3 & 1 & 2 & 3 & 2 & 1 & 3 & 3 \\
\hline 40 & 2 & 2 & 2 & 3 & 1 & 2 & 1 & 3 & 1 & 2 & 3 & 1 & 3 & 2 & 2 & 3 \\
\hline 41 & 2 & 2 & 2 & 3 & 1 & 2 & 1 & 3 & 2 & 3 & 1 & 2 & 1 & 3 & 3 & 1 \\
\hline 42 & 2 & 2 & 2 & 3 & 1 & 2 & 1 & 3 & 3 & 1 & 2 & 3 & 2 & 1 & 1 & 2 \\
\hline 43 & 2 & 2 & 3 & 1 & 2 & 3 & 2 & 1 & 1 & 2 & 3 & 1 & 3 & 2 & 3 & 2 \\
\hline 44 & 2 & 2 & 3 & 1 & 2 & 3 & 2 & 1 & 2 & 3 & 1 & 2 & 1 & 3 & 1 & 3 \\
\hline 45 & 2 & 2 & 3 & 1 & 2 & 3 & 2 & 1 & 3 & 1 & 2 & 3 & 2 & 1 & 2 & 1 \\
\hline 46 & 2 & 3 & 1 & 3 & 2 & 3 & 1 & 2 & 1 & 3 & 2 & 3 & 1 & 2 & 1 & 1 \\
\hline 47 & 2 & 3 & 1 & 3 & 2 & 3 & 1 & 2 & 2 & 1 & 3 & 1 & 2 & 3 & 2 & 2 \\
\hline 48 & 2 & 3 & 1 & 3 & 2 & 3 & 1 & 2 & 3 & 2 & 1 & 2 & 3 & 1 & 3 & 3 \\
\hline 49 & 2 & 3 & 2 & 1 & 3 & 1 & 2 & 3 & 1 & 3 & 2 & 3 & 1 & 2 & 2 & 3 \\
\hline 50 & 2 & 3 & 2 & 1 & 3 & 1 & 2 & 3 & 2 & 1 & 3 & 1 & 2 & 3 & 3 & 1 \\
\hline 51 & 2 & 3 & 2 & 1 & 3 & 1 & 2 & 3 & 3 & 2 & 1 & 2 & 3 & 1 & 1 & 2 \\
\hline 52 & 2 & 3 & 3 & 2 & 1 & 2 & 3 & 1 & 1 & 3 & 2 & 3 & 1 & 2 & 3 & 2 \\
\hline 53 & 2 & 3 & 3 & 2 & 1 & 2 & 3 & 1 & 2 & 1 & 3 & 1 & 2 & 3 & 1 & 3 \\
\hline 54 & 2 & 3 & 3 & 2 & 1 & 2 & 3 & 1 & 3 & 2 & 1 & 2 & 3 & 1 & 2 & 1 \\
\hline
\end{tabular}


Table 12. Optimal values of functions and parameters for the generated trials with the Taguchi L 54 design

\begin{tabular}{|c|c|c|c|c|c|c|c|c|c|}
\hline Trial & $n$ & $h$ & $l$ & $k$ & $\theta$ & $\phi$ & ETC & $A R L_{0}$ & $A R L_{1}$ \\
\hline 1 & 18 & 0.36 & 2.82 & 14 & 0.00 & 0.67 & 2504.11 & 263.43 & 9.75 \\
\hline 2 & 3 & 0.71 & 2.81 & 7 & 0.09 & 0.83 & 4962.00 & 272.84 & 10.51 \\
\hline 3 & 1 & 2.50 & 2.85 & 2 & 0.00 & 0.80 & 8425.27 & 362.29 & 9.41 \\
\hline 4 & 1 & 0.16 & 2.82 & 31 & 0.03 & 0.80 & 4159.14 & 239.96 & 6.21 \\
\hline 5 & 1 & 0.13 & 2.91 & 53 & 0.01 & 0.83 & 6120.72 & 371.11 & 6.47 \\
\hline 6 & 1 & 0.25 & 2.90 & 20 & 0.14 & 0.77 & 6812.36 & 281.70 & 7.82 \\
\hline 7 & 3 & 0.24 & 2.83 & 21 & 0.00 & 0.70 & 7675.94 & 223.35 & 3.13 \\
\hline 8 & 1 & 0.10 & 3.52 & 50 & 0.00 & 0.91 & 8025.83 & 938.37 & 3.60 \\
\hline 9 & 1 & 0.33 & 3.01 & 15 & 0.14 & 0.63 & 9778.77 & 381.78 & 6.67 \\
\hline 10 & 10 & 2.51 & 3.27 & 2 & 0.08 & 0.56 & 3515.04 & 744.80 & 37.65 \\
\hline 11 & 9 & 0.37 & 2.75 & 14 & 0.29 & 0.67 & 5454.65 & 207.03 & 16.53 \\
\hline 12 & 1 & 0.12 & 2.73 & 46 & 0.03 & 0.86 & 8310.50 & 340.80 & 13.51 \\
\hline 13 & 3 & 1.10 & 3.42 & 5 & 0.20 & 0.61 & 7966.69 & 850.76 & 37.11 \\
\hline 14 & 1 & 0.10 & 3.68 & 50 & 0.10 & 0.85 & 8742.72 & 1076.67 & 18.75 \\
\hline 15 & 2 & 0.32 & 2.89 & 16 & 0.38 & 0.76 & 8863.57 & 243.40 & 17.58 \\
\hline 16 & 12 & 2.51 & 3.14 & 2 & 0.31 & 0.60 & 8709.08 & 555.68 & 20.34 \\
\hline 17 & 1 & 0.10 & 3.20 & 50 & 0.00 & 0.89 & 6494.10 & 613.84 & 4.10 \\
\hline 18 & 1 & 0.13 & 3.01 & 48 & 0.00 & 0.86 & 5589.80 & 384.61 & 3.81 \\
\hline 19 & 1 & 0.10 & 2.08 & 50 & 0.07 & 0.95 & 7793.65 & 212.03 & 29.69 \\
\hline 20 & 11 & 5.01 & 2.45 & 1 & 0.10 & 0.75 & 13801.74 & 201.48 & 39.69 \\
\hline 21 & 1 & 0.10 & 2.25 & 50 & 0.12 & 0.92 & 10824.46 & 207.06 & 31.98 \\
\hline 22 & 4 & 0.36 & 2.34 & 14 & 0.10 & 0.91 & 7074.87 & 232.68 & 28.41 \\
\hline 23 & 3 & 0.63 & 2.60 & 8 & 0.15 & 0.81 & 9194.70 & 286.59 & 34.49 \\
\hline 24 & 1 & 0.10 & 2.27 & 50 & 0.10 & 0.94 & 5154.64 & 213.40 & 27.55 \\
\hline 25 & 9 & 2.54 & 3.33 & 2 & 0.24 & 0.75 & 5620.90 & 757.60 & 23.07 \\
\hline 26 & 1 & 0.34 & 3.58 & 15 & 0.32 & 0.81 & 6287.75 & 1018.91 & 34.61 \\
\hline 27 & 9 & 1.68 & 3.26 & 3 & 0.13 & 0.78 & 3089.80 & 692.93 & 15.28 \\
\hline 28 & 1 & 0.10 & 3.61 & 50 & 0.00 & 0.22 & 5700.61 & 1006.24 & 1.44 \\
\hline 29 & 1 & 0.28 & 3.14 & 18 & 0.95 & 0.63 & 3557.90 & 495.52 & 4.77 \\
\hline 30 & 1 & 0.36 & 3.54 & 14 & 0.12 & 0.38 & 6689.60 & 956.43 & 1.71 \\
\hline 31 & 1 & 0.10 & 3.43 & 50 & 0.00 & 1.00 & 10125.33 & 898.60 & 1.30 \\
\hline 32 & 1 & 0.20 & 3.05 & 25 & 0.72 & 0.54 & 7619.16 & 410.48 & 3.14 \\
\hline 33 & 1 & 0.36 & 2.91 & 14 & 0.16 & 0.28 & 8049.21 & 261.20 & 1.38 \\
\hline 34 & 1 & 1.45 & 3.22 & 4 & 0.00 & 0.58 & 7434.74 & 618.33 & 1.02 \\
\hline 35 & 1 & 5.00 & 4.46 & 1 & 0.28 & 0.27 & 4261.63 & 1200.19 & 3.92 \\
\hline 36 & 1 & 1.00 & 2.80 & 5 & 0.36 & 0.39 & 4486.87 & 209.59 & 1.70 \\
\hline 37 & 1 & 0.22 & 3.11 & 23 & 0.18 & 0.35 & 3706.19 & 488.52 & 1.74 \\
\hline 38 & 1 & 1.01 & 2.93 & 5 & 0.03 & 0.00 & 5992.26 & 303.96 & 1.14 \\
\hline 39 & 1 & 0.56 & 3.22 & 10 & 0.00 & 0.17 & 4708.67 & 627.35 & 1.29 \\
\hline 40 & 1 & 0.31 & 2.84 & 16 & 0.49 & 0.39 & 7211.32 & 208.91 & 2.05 \\
\hline 41 & 1 & 1.08 & 2.93 & 10 & 0.00 & 0.29 & 5817.19 & 287.44 & 1.15 \\
\hline 42 & 1 & 0.33 & 3.33 & 15 & 0.53 & 0.66 & 4270.00 & 755.27 & 3.16 \\
\hline 43 & 2 & 0.63 & 3.69 & 8 & 0.00 & 0.59 & 9316.07 & 1039.87 & 1.21 \\
\hline 44 & 1 & 0.10 & 3.88 & 50 & 0.00 & 0.56 & 9170.05 & 1145.71 & 1.25 \\
\hline 45 & 1 & 0.20 & 3.78 & 25 & 0.36 & 0.62 & 6265.97 & 1089.08 & 2.59 \\
\hline 46 & 5 & 0.28 & 3.34 & 18 & 0.68 & 0.56 & 8372.14 & 835.32 & 4.39 \\
\hline 47 & 1 & 0.33 & 3.01 & 15 & 0.23 & 0.08 & 7495.27 & 450.49 & 1.47 \\
\hline 48 & 1 & 0.26 & 3.21 & 19 & 0.46 & 0.44 & 9043.79 & 722.90 & 2.94 \\
\hline 49 & 1 & 0.56 & 3.70 & 9 & 0.51 & 0.44 & 6522.14 & 1069.69 & 4.09 \\
\hline 50 & 1 & 2.46 & 2.74 & 3 & 0.00 & 0.02 & 3314.77 & 213.47 & 1.05 \\
\hline 51 & 1 & 1.67 & 3.21 & 3 & 0.37 & 0.51 & 3881.96 & 710.71 & 2.93 \\
\hline 52 & 1 & 0.13 & 3.35 & 54 & 0.00 & 0.23 & 8081.50 & 749.39 & 1.28 \\
\hline 53 & 1 & 0.10 & 2.99 & 50 & 0.00 & 0.30 & 6265.11 & 367.65 & 1.16 \\
\hline 54 & 1 & 0.20 & 2.94 & 31 & 0.00 & 0.27 & 4610.97 & 334.92 & 1.18 \\
\hline
\end{tabular}


Table 13. ANOVA for ETC

\begin{tabular}{|c|c|c|c|c|c|}
\hline Source & D.F. & Adj. S.S. & Adj. M.S. & $\mathrm{F}$ & $P$-value \\
\hline Model $^{*}$ & 8 & 206518199 & 25814775 & 18.48 & 0.000 \\
\hline A & 1 & 6672799 & 6672799 & 4.78 & 0.034 \\
\hline D & 1 & 5003314 & 5003314 & 3.58 & 0.065 \\
\hline $\mathrm{E}$ & 1 & 12282596 & 12282596 & 8.79 & 0.005 \\
\hline $\mathrm{F}$ & 1 & 88713102 & 88713102 & 63.52 & 0.000 \\
\hline K & 1 & 51177437 & 51177437 & 36.64 & 0.000 \\
\hline $\mathrm{L}$ & 1 & 5289052 & 5289052 & 3.79 & 0.058 \\
\hline $\mathrm{P}$ & 1 & 19539063 & 19539063 & 13.99 & 0.001 \\
\hline Q & 1 & 17840836 & 17840836 & 12.77 & 0.001 \\
\hline Residual Error & 45 & 62852438 & 1396721 & & \\
\hline Total & 53 & 269370637 & & & \\
\hline
\end{tabular}

Table 14. Effects of independent parameters on ETC

\begin{tabular}{ccccccccc}
\hline Factor & $\mathrm{A}$ & $\mathrm{B}$ & $\mathrm{C}$ & $\mathrm{D}$ & $\mathrm{E}$ & $\mathrm{F}$ & $\mathrm{G}$ & $\mathrm{H}$ \\
\hline Level 1 & 7072 & 6466 & 6714 & 6246 & 7286 & 5690 & 6381 & 6808 \\
Level 2 & 6369 & 6672 & 6717 & 6924 & 6758 & 5643 & 6929 & 6555 \\
Level 3 & - & 7024 & 6731 & 6992 & 6118 & 8829 & 6852 & 6799 \\
Delta & 703 & 558 & 17 & 746 & 1168 & 3186 & 548 & 253 \\
Rank & 8 & 10 & 16 & 7 & 5 & 1 & 11 & 12 \\
\hline Factor & $\mathrm{J}$ & $\mathrm{K}$ & $\mathrm{L}$ & $\mathrm{M}$ & $\mathrm{N}$ & $\mathrm{O}$ & $\mathrm{P}$ & $\mathrm{Q}$ \\
\hline Level 1 & 6749 & 5631 & 6197 & 6829 & 6516 & 6686 & 6063 & 5901 \\
Level 2 & 6810 & 6516 & 7002 & 6675 & 6552 & 6644 & 6564 & 6952 \\
Level 3 & 6603 & 8016 & 6964 & 6659 & 7094 & 6832 & 7536 & 7309 \\
Delta & 207 & 2385 & 805 & 170 & 579 & 188 & 1473 & 1408 \\
Rank & 13 & 2 & 6 & 15 & 9 & 14 & 3 & 4 \\
\hline
\end{tabular}

